\title{
Inhibition of SARS-CoV-2 infection in human iPSC-derived cardiomyocytes by targeting the Sigma-1 receptor disrupts cytoarchitecture and beating
}

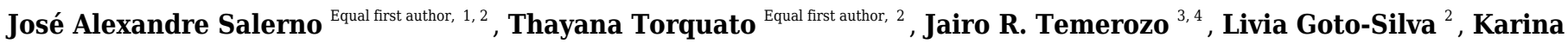
Karmirian $^{1,2}$, Mayara A. Mendes ${ }^{2}$, Carolina Q. Sacramento ${ }^{5,6}$, Natalia Fintelman-Rodrigues ${ }^{5,6}$, Letícia R Q Souza ${ }^{2}$, Isis M Ornelas ${ }^{2}$, Carla P Veríssimo ${ }^{1}$, Luiz Guilherme H S Aragão ${ }^{2}$, Gabriela Vitória ${ }^{2}$, Carolina S G Pedrosa ${ }^{2}$, Suelen da Silva Gomes Dias ${ }^{5}$, Vinicius Cardoso Soares ${ }^{1,5}$, Teresa Puig-Pijuan ${ }^{2,7}$, Vinícius Salazar ${ }^{8}$, Rafael Dariolli ${ }^{9,10}$, Diogo Biagi ${ }^{10}$, Daniel R Furtado ${ }^{2}$, Luciana Barreto Chiarini ${ }^{7}$, Helena L. Borges ${ }^{1}$, Patrícia T. Bozza ${ }^{5}$, Marilia Zaluar P Guimarães ${ }^{1,2}$, Thiago M L Souza ${ }^{5,6}$, Stevens K Rehen ${ }^{\text {Corresp. } 2,11}$

1 Institute of Biomedical Sciences, Federal University of Rio Janeiro (UFRJ), Rio de Janeiro, Brazil

2 D'Or Institute for Research and Education (IDOR), Rio de Janeiro, Brazil

3 National Institute for Science and Technology on Neuroimmunomodulation (INCT/NIM), Oswaldo Cruz Institute (IOC), Oswaldo Cruz Foundation (Fiocruz), Rio de Janeiro, Brazil

4 Laboratory on Thymus Research, Oswaldo Cruz Institute (IOC), Oswaldo Cruz Foundation (Fiocruz), Rio de Janeiro, Brazil

5 Immunopharmacology Laboratory, Oswaldo Cruz Institute (IOC), Oswaldo Cruz Foundation (Fiocruz), Rio de Janeiro, Brazil

6 National Institute for Science and Technology on Innovation in Diseases of Neglected Populations (INCT/IDPN), Center for Technological Development in Health (CDTS), Oswaldo Cruz Foundation (Fiocruz), Rio de Janeiro, Brazil

7 Carlos Chagas Filho Institute of Biophysics (IBCCF), Federal University of Rio de Janeiro (UFRJ), Rio de Janeiro, Brazil

8 Department of Systems and Computer Engineering, COPPE, Federal University of Rio de Janeiro (UFRJ), Rio de Janeiro, Brazil

9 Department of Pharmacological Sciences, Icahn School of Medicine at Mount Sinai, New York, New York, United States

10 PluriCell Biotech, São Paulo, Brazil

11 Department of Genetics, Institute of Biology, Universidade Federal do Rio de Janeiro, Rio de Janeiro, Brazil

Corresponding Author: Stevens K Rehen

Email address: srehen@lance-ufrj.org

SARS-CoV-2 infects cardiac cells and causes heart dysfunction. Conditions such as myocarditis and arrhythmia have been reported in COVID-19 patients. The Sigma-1 receptor (S1R) is a ubiquitously expressed chaperone that plays a central role in cardiomyocyte function. SIR has been proposed as a therapeutic target because it may affect SARS-CoV-2 replication, however, the impact of the inhibition of S1R in human cardiomyocytes remains to be described. In this study, we investigated the consequences of S1R inhibition in iPS-derived human cardiomyocytes (hiPSC-CM). SARS-CoV-2 infection in hiPSC-CM was productive and reduced cell survival. S1R inhibition decreased both the number of infected cells and viral particles after 48 hours. S1R inhibition also prevented the release of pro-inflammatory cytokines and cell death. Although the S1R antagonist NE-100 triggered those protective effects, it compromised cytoskeleton integrity by downregulating the expression of structural-related genes and reducing beating frequency. Our findings suggest that the detrimental effects of S1R inhibition in human 
cardiomyocytes' integrity may abrogate its therapeutic potential against COVID and should be carefully considered. 


\section{Inhibition of SARS-CoV-2 infection in human iPSC-}

2 derived cardiomyocytes by targeting the Sigma-1

3 receptor disrupts cytoarchitecture and beating

4

José Alexandre Salerno ${ }^{1,2 \dagger}$, Thayana Torquato ${ }^{1 \dagger}$, Jairo R. Temerozo ${ }^{3,4}$, Livia Goto-Silva $^{1}$, Karina Karmirian $^{1,2}$, Mayara A. Mendes ${ }^{1}$, Carolina Q. Sacramento ${ }^{5,6}$, Natalia Fintelman-Rodrigues ${ }^{5,6}$, Letícia R Q Souza $^{1}$, Isis M Ornelas ${ }^{1}$, Carla P Veríssimo ${ }^{2}$, Luiz Guilherme H S Aragão ${ }^{1}$, Gabriela Vitória $^{1}$, Carolina SG Pedrosa ${ }^{1}$, Suelen da Silva Gomes Dias ${ }^{5}$, Vinicius Cardoso Soares ${ }^{2,5}$, Teresa Puig-Pijuan ${ }^{1,7}$, Vinícius Salazar ${ }^{8}$, Rafael Dariolli ${ }^{9}, 10$, Diogo Biagi ${ }^{10}$, Daniel Rodrigues Furtado ${ }^{1}$, Luciana Barreto Chiarini ${ }^{7}$, Helena L. Borges ${ }^{2}$, Patrícia T. Bozza ${ }^{5}$, Marília Zaluar P. Guimarães ${ }^{1,2}$, Thiago M L Souza ${ }^{5,6}$, Stevens K. Rehen ${ }^{1,11^{*}}$.

${ }^{1}$ D'Or Institute for Research and Education (IDOR), Rio de Janeiro, Brazil.

${ }^{2}$ Institute of Biomedical Sciences, Federal University of Rio de Janeiro (UFRJ), Rio de Janeiro, Brazil.

${ }^{3}$ National Institute for Science and Technology on Neuroimmunomodulation (INCT/NIM), Oswaldo Cruz Institute (IOC), Oswaldo Cruz Foundation (Fiocruz), Rio de Janeiro, Brazil.

${ }^{4}$ Laboratory on Thymus Research, Oswaldo Cruz Institute (IOC), Oswaldo Cruz Foundation (Fiocruz), Rio de Janeiro, Brazil.

${ }^{5}$ Immunopharmacology Laboratory, Oswaldo Cruz Institute (IOC), Oswaldo Cruz Foundation (Fiocruz), Rio de Janeiro, Brazil.

${ }^{6}$ National Institute for Science and Technology on Innovation in Diseases of Neglected Populations (INCT/IDPN), Center for Technological Development in Health (CDTS), Oswaldo Cruz Foundation (Fiocruz), Rio de Janeiro, Brazil.

${ }^{7}$ Carlos Chagas Filho Institute of Biophysics (IBCCF), Federal University of Rio de Janeiro (UFRJ), Rio de Janeiro, Brazil.

${ }^{8}$ Department of Systems and Computer Engineering, COPPE, Federal University of Rio de Janeiro (UFRJ), Rio de Janeiro, Brazil.

${ }^{9}$ Department of Pharmacological Sciences, Icahn School of Medicine at Mount Sinai, New York, NY, USA

${ }^{10}$ Pluricell Biotech, São Paulo, Brazil.

${ }^{11}$ Department of Genetics, Institute of Biology, Federal University of Rio de Janeiro (UFRJ), Rio de Janeiro, Brazil.

Corresponding Author:

Stevens K. Rehen ${ }^{1,11}$

Diniz Cordeiro 30, Rio de Janeiro, Rio de Janeiro/RJ, 22281-100, Brazil

Email address: srehen@lance-ufrj.org 
39

40

41

42

43

44

45

46

47

48

49

50

51

52

53

54

55

56

57

58

59

60

61

62

63

64

65

66

67

68

69

70

71

72

73

74

75

76

77

78

\section{Abstract}

SARS-CoV-2 infects cardiac cells and causes heart dysfunction. Conditions such as myocarditis and arrhythmia have been reported in COVID-19 patients. The Sigma-1 receptor (S1R) is a ubiquitously expressed chaperone that plays a central role in cardiomyocyte function. S1R has been proposed as a therapeutic target because it may affect SARS-CoV-2 replication, however, the impact of the inhibition of S1R in human cardiomyocytes remains to be described. In this study, we investigated the consequences of S1R inhibition in iPS-derived human cardiomyocytes (hiPSC-CM). SARS-CoV-2 infection in hiPSC-CM was productive and reduced cell survival. S1R inhibition decreased both the number of infected cells and viral particles after 48 hours. S1R inhibition also prevented the release of pro-inflammatory cytokines and cell death. Although the S1R antagonist NE-100 triggered those protective effects, it compromised cytoskeleton integrity by downregulating the expression of structural-related genes and reducing beating frequency. Our findings suggest that the detrimental effects of S1R inhibition in human cardiomyocytes' integrity may abrogate its therapeutic potential against COVID and should be carefully considered.

\section{Introduction}

COVID-19 is an airborne infectious disease caused by the Severe Acute Respiratory Syndrome Coronavirus 2 (SARS-CoV-2). Since the first patients were diagnosed, myocardial injury following SARS-CoV-2 infection has been reported increasing the in-hospital mortality (of $51.2 \%$ ) in comparison to cases without cardiac injury (of 4.5\%) (Huang et al., 2020; Gnecchi et al., 2020; Shi et al., 2020). Pre-existing cardiovascular comorbidities are related to worse clinical outcomes and, together with diabetes, are the most common chronic conditions among hospitalized COVID-19 patients (Yang et al., 2020; Magadum \& Kishore, 2020). Hence, there is a higher prevalence of cardiovascular complications as extrapulmonary COVID-19. Together, these data reinforce that therapeutic approaches targeting SARS-CoV-2 infection must not only seek to diminish cardiac damage by COVID-19, but also consider the eventual drug-induced damage to the heart, which would in turn aggravate the disease (Pellicori et al., 2021).

Human induced pluripotent stem cell-derived cardiomyocytes (hiPSC-CMs) reproduce key features of human myocardial cells, such as expression of lineage-specific markers, sarcomeric and cytoskeletal organization, subcellular structures, and contractility (Karakikes et al., 2015). Given the scarcity of cardiomyocytes from other sources and the suitability of hiPSC-CMs as a model in vitro for cardiac diseases, they are useful tools to investigate SARS-CoV-2 infection and to test drugs that may eventually prevent cardiac susceptibility. Indeed they were used for these purposes and it was shown that the new coronavirus infects these cells and causes mechanical and electrical impairment (Sharma et al., 2020; Choi et al., 2020; Wong et al., 2020; Perez-Bermejo et al., 2021; Marchiano et al., 2021). Also, these cells are reliable to evaluate drug-induced cardiotoxicity, which is one of the main causes of drug withdrawal from the market due to fatal side effects (Chaudhari et al., 2016; Sharma et al., 2018; Choi et al., 2020). hiPSC- 
79 CMs can be used as a preclinical model to investigate the safety of emerging therapeutics and

80 more effective treatments for COVID-19.

81

82 Compounds from drug repurposing studies have been proposed to display antiviral activity 83 against SARS-CoV-2 (Lovato et al., 2020). Negative modulators of the Sigma-1 receptor (S1R)

84 interact with the Non-Structural Protein 6 (NSP6) from SARS-CoV-2 (Gordon et al., 2020b;

85 Hashimoto, 2021). Knockout of S1R decreased the replication of SARS-CoV-2 in Caco-2 cells

86 (Gordon et al., 2020a). The NSP6 is one of the proteins assembled into the replication complex

87 built in the endoplasmic reticulum (ER) of host cells infected by other coronaviruses (Cottam et

88 al., 2011a; Cottam, Whelband \& Wileman, 2014). The role of NSP6 in the intracellular viral

89 cycle has been associated with the formation of vesicles in sites of replication and

90 autophagosomes to favor the replication in the ER and ER-derived vesicles (Cottam et al.,

91 2011b; Cottam, Whelband \& Wileman, 2014). Interestingly, this is the subcellular localization

92 where S1R is enriched, especially within the ER-mitochondrion contact (Dussossoy et al., 1999;

93 Hayashi \& Su, 2003a,b, 2007; Su et al., 2010; Brune, Pricl \& Wünsch, 2013; Rousseaux \&

94 Greene, 2016; Gordon et al., 2020b). However, this receptor is an ER chaperone that acts

95 assisting in the folding of host proteins, either during their synthesis or function, and controlling

96 calcium homeostasis (Morales-Lázaro, González-Ramírez \& Rosenbaum, 2019). S1R is also a

97 key intracellular amplifier of signal transduction in different pathways including bioenergetics

98 and response to cellular stress (Hayashi \& Su, 2007; Hayashi et al., 2009; Hayashi, 2015).

99 Therefore, although targeting this receptor was shown to block SARS-CoV-2 replication, it may

100 also lead to harmful side effects because of its involvement in vital cellular functions.

101

102

103

In the context of cardiac tissue, S1R plays important roles in cardioprotection against

104 maladaptive ER stress responses, apoptosis after ischemic injuries and hypertrophy (Tagashira \& Fukunaga, 2012; Tagashira et al., 2013, 2014; Hirano, Tagashira \& Fukunaga, 2014; Lewis et al.,

106

107

108

109

110

111

112

113

114

115

116

117

118 2020). Research both in vivo and in vitro have proposed calcium homeostasis and suppression of ER stress induced toxicity as possible events related to S1R cardiovascular function in rodents (Bhuiyan \& Fukunaga, 2009; Tagashira et al., 2013; Shinoda et al., 2016a; Qin et al., 2019). Accordingly, depletion of S1R has been demonstrated to cause mitochondrial damage and contractile dysfunction (Abdullah et al., 2018, 2020).

Drugs that bind to Sigma receptors, even as an off-target, have been considered as potential therapeutics to prevent or to treat COVID-19 (Reznikov et al., 2020; Vela, 2020). Some of these compounds have been reported to exhibit antiviral activity against other coronaviruses, together with cardiotoxicity and induction of arrhythmias (Chen, Wang \& Lin, 2006; Page et al., 2016). Others, however, have stated that the antiviral properties of these compounds are due to their physicochemical properties rather than their pharmacological interaction with S1R (Tummino et al., 2021). Therefore, the modulation of S1R is in the spotlight of alternative approaches to treat COVID-19 but it remains to be explored in the perspective of efficiency and safety in human 
119 heart cells. In this study, we investigated the consequences of the inhibition of S1R in hiPSC-

120 CMs. Inhibition of S1R led to transcriptional modifications of myofibril-associated genes,

121 aberrant changes in the cytoskeleton and decreased beating frequency, despite reducing infection

122 and viral replication of SARS-CoV-2 and preventing viral-associated cytokine release and cell

123 death. These results provide new insights about targeting S1R as a strategy against COVID-19

124 and possible adverse cardiac outcomes.

125

126

127

\section{Materials \& Methods}

128 Fresh human iPSCs-derived cardiomyocytes were purchased from Pluricell (São Paulo, Brazil)

129 and the protocol for cardiomyocyte differentiation is described (Cruvinel et al., 2020). Upon arrival, cardiomyocytes were allowed to regain contractility and maintained at $37^{\circ} \mathrm{C}$ in a humidified atmosphere with 5\% CO2. Cardiomyocytes were used between days 30 to 40 of differentiation.

133

134

\section{$\underline{\text { Chemicals }}$}

135

4-Methoxy-3-(2-phenylethoxy)-N,N-dipropylbenzeneethanamine hydrochloride (NE-100 hydrochloride) was purchased from Tocris (3133). Stock and work solutions were prepared using 100\% dimethyl sulfoxide sterile-filtered (DMSO; D2650 - Sigma-Aldrich).

\section{Flow Cytometry}

140 Cardiomyocytes were plated on 6-well plates coated with GELTREX and cultivated for 7 days.

141 After cell dissociation, cells were fixed with 1\% paraformaldehyde (PFA), permeabilized with

142 Triton 0.1\% (Sigma Aldrich) and Saponin 0.1\% (Sigma Aldrich) and stained with the antibodies 143 anti-TNNT2 (1:2500; Thermo Fisher, MA5-12960) and anti-OCT4 (1:200, Thermo Fisher, 144 MA5-14845). FC data was acquired using a Canto BD flow cytometer for each batch of 145 differentiation and analyzed using the FlowJo Software considering 1\%-2\% of false-positive 146 events.

147

\section{SARS-CoV-2 Propagation}

149 SARS-CoV-2 was expanded in Vero E6 cells from an isolate obtained from a nasopharyngeal swab of a confirmed case in Rio de Janeiro, Brazil (GenBank accession no. MT710714). The National Review Board approved the study protocol (CONEP 30650420.4.1001.0008) for clinical samples, and informed consent was obtained from all participants or patients' representatives. Viral isolation was performed after a single passage in cell culture in $150 \mathrm{~cm}^{2}$ flasks with high glucose DMEM 2\% FBS. Observations for cytopathic effects were performed daily and peaked 4 to 5 days after infection. All procedures related to virus culture were handled 
159

160

161

162

163

164

165

166

167

168

169

170

171

172

173

174

175

176

177

178

179

180

181

182

183

184

185

186

187

188

189

190

191

192

193

194

195

196

197

198

Infections and virus titration

Cardiomyocytes were infected with SARS-CoV-2 at MOI of 0.1 in CDM3 media without serum. After 1 hour, cells were washed and incubated with complete medium with treatments or not. For virus titration, monolayers of Vero E6 cells $\left(2 \times 10^{4}\right.$ cells/well $)$ in 96-well plates were infected with serial dilutions of supernatants containing SARS-CoV-2 for 1 hour at $37^{\circ} \mathrm{C}$. A semi-solid high glucose DMEM medium containing 2\% FSB and 2.4\% carboxymethylcellulose was added and cultures were incubated for 3 days at $37^{\circ} \mathrm{C}$. Then, cells were fixed with $10 \%$ formalin for $2 \mathrm{~h}$ at room temperature. The cell monolayer was stained with $0.04 \%$ solution of crystal violet in $20 \%$ ethanol for $1 \mathrm{~h}$. Plaque numbers were scored in at least 3 replicates per dilution by independent readers blinded to the experimental group and the virus titers were determined by PFU per milliliter (PFU/ml).

$\underline{\text { Immunocytochemistry and Fluorescence Image Analysis }}$

Cells were fixed using 4\% PFA solution (Sigma-Aldrich) for $1 \mathrm{~h}$, washed with $1 \mathrm{X}$ PBS and then incubated with permeabilization/blocking solution $(0.3 \%$ Triton $\mathrm{X}-100 / 3 \%$ bovine serum albumin) for $1 \mathrm{~h}$. Primary antibodies were diluted in blocking solution and incubated at $4^{\circ} \mathrm{C}$ overnight, namely anti-SARS-CoV-2 convalescent serum (1:1000); anti-SARS-CoV-2 spike protein monoclonal antibody (SP) (1:500, G632604 - Genetex); anti-cardiac troponin T (cTnT) (1:500, MA5-12960 - Invitrogen), anti-VDAC1/Porin (1:100, ab34726 - Abcam), anti-Calnexin (1:50, \#2433 - Cell Signaling Technology) and anti-Sigma1R B-5 (1:100, SC-137075 - Santa Cruz Biotechnology). The use of the convalescent serum from COVID-19 patients was approved by CAAE number: 30650420.4.1001.0008. Next, hiPSC-CMs were washed with PBS 1X and incubated with the secondary antibodies diluted in blocking solution: goat anti-Human Alexa Fluor 647 (1:400; A-21445 - Invitrogen), goat anti-Rabbit Alexa Fluor 546 and goat anti-Mouse Alexa Fluor 488 (1:400; A-11001 - Invitrogen) for $1 \mathrm{~h}$ at room temperature. Actin filaments were stained with Alexa Fluor 568 phalloidin (1:10; A-12380 - Life Technologies) for $1 \mathrm{~h}$. Nuclei were stained with $300 \mathrm{nM}$ 4'-6-diamino-2-phenylindole (DAPI) for 5 minutes and each well was mounted with 50\% PBS-Glycerol.

For quantitative analysis, images were acquired using Operetta ${ }^{\circledR}$ High-Content Screening System (Perkin Elmer) with a 20x long working distance (WD) objective lens from at least 10 fields per well. For cell surface area measurement, images of F-actin stained cardiomyocytes were segmented using Cellpose and the area was measured using NIH ImageJ software (Stringer et al., 2021). For the other analyses, data were evaluated using the Columbus ${ }^{\mathrm{TM}}$ Image Data Storage and Analysis System (Perkin Elmer) for image segmentation and object detection. Fluorescence threshold was set to determine positive and negative cells for each marker. Representative immunostaining images were acquired on a Leica TCS-SP8 confocal microscope using a 63x oilimmersion objective lens. 
199

200

201

202

203

204

205

206

207

208

209

210

211

212

213

214

215

216

217

218

219

220

221

222

223

224

225

226

227

228

229

230

231

232

233

234

235

236

237

238

Measurements of Cell Death and Cytokines

Monolayers of hiPSC-CMs in 96-well plates (70-90\% confluence) were treated with various concentrations of NE-100. The neutral red assay was performed, and viability was estimated by the percentage relative to untreated condition (vehicle) using the mean of 6 technical replicates per experiment.

The levels of IL-6, IL-8, and TNF- $\alpha$ were quantified in the supernatants from uninfected and SARS-CoV-2-infected hiPSC-CMs by ELISA (R\&D Systems), following manufacturer's instructions. Control groups (mock and cells infected with SARS-CoV-2 only) were also analyzed in Aragão et al., 2021. The results were obtained as picograms per milliliter (pg/ml) and are expressed as fold-change relative to untreated uninfected control. Cell death was determined according to the activity of lactate dehydrogenase (LDH) in the culture supernatants using a CytoTox ${ }^{\circledR}$ Kit (Promega, USA) according to the manufacturer's instructions. Supernatants were centrifuged at 5,000 rpm for 1 minute, to remove cellular debris.

\section{Gene Expression Analysis}

Total RNA was isolated using TRIzol, according to the manufacturer's recommendations (Thermo Fisher Scientific) and digested using DNase I, Amplification Grade (Invitrogen), following the manufacturer's instructions. DNase-treated RNA samples $(1 \mu \mathrm{g})$ were converted to complementary DNA (cDNA) using the M-MLV enzyme (Thermo Fisher Scientific). Qualitative endpoint PCR reactions were executed with the following primer sequences: S1R (forward 5'AGTAGGACCATGCACTCACACC-3'; reverse: 5'- CCCCATCCTTAACTCTAGAACC-3'). Glyceraldehyde-3-phosphate Dehydrogenase (GAPDH; forward: 5'-

TTCGACAGTCAGCCGCATC-3'; reverse: 5'-GACTCCACGACGTACTCAGC-3') was used as the endogenous housekeeping control gene. Each PCR reaction was performed in a $10 \mu \mathrm{L}$ mixture containing 0.25 U GoTaq G2 Hot Start Polymerase (Promega), 1x GoTaq G2 Buffer, 1.5 $\mathrm{mM} \mathrm{MgCl} 2$ (Invitrogen), $200 \mathrm{nM}$ of each primer (forward and reverse), $200 \mu \mathrm{M}$ dNTP mixture containing the four deoxyribonucleotides (dATP, dCTP, dTTP, and dGTP), and $10 \mathrm{ng}$ of cDNA template. Appropriate negative controls and genomic DNA positive controls were incorporated into each experiment. Amplification thermal program included an initial denaturation step of $95^{\circ} \mathrm{C}$ for $3 \mathrm{~min}$ and 40 cycles of $95^{\circ} \mathrm{C}$ for $15 \mathrm{~s}, 58^{\circ} \mathrm{C}$ for $15 \mathrm{~s}$ and $72^{\circ} \mathrm{C}$ for $15 \mathrm{~s}$ using the ProFlex ${ }^{\text {TM }}$ PCR System Thermal Cycler (Applied Biosystems). Subsequently, total amount of PCR product was separated by electrophoresis at $120 \mathrm{~V}$ for $30 \mathrm{~min}$ in $2 \%$ agarose gel diluted in $1 X$ Tris-acetate EDTA buffer (w/v) and stained with $0.01 \%$ of SYBR Safe (Thermo Fisher). For real-time quantitative PCR, the reactions were conducted in three replicates with a final volume of $10 \mu \mathrm{L}$ containing 1X GoTaq qPCR Master Mix (Promega), $300 \mathrm{nM} \mathrm{CXR} \mathrm{Reference}$ Dye, 200nM of each SYBR green designed primers: Angiotensin I Converting Enzyme 2 (ACE2; forward: 5'-CGAAGCCGAAGACCTGTTCTA-3'; reverse: 5'GGGCAAGTGTGGACTGTTCC-3'); Natriuretic Peptide A (ANP; forward: 5'CAACGCAGACCTGATGGATTT-3'; reverse: 5'-AGCCCCCGCTTCTTCATTC-3'); Spliced 
239 X-Box Binding Protein 1 (sXBP1; forward: 5'- CTGAGTCCGAATCAGGTGCAG-3'; reverse:

240 5'-AtCCATGGGGAGATGTTCTGG-3'); Unspliced X-Box Binding Protein 1 (usXBP1;

241 forward: 5'-CAGCACTCAGACTACGTGCA-3'; reverse: 5'-

242 ATCCATGGGGAGATGTTCTGG-3'); Total X-Box Binding Protein 1 (totalXBP1; forward: 5'-

243 TGGCCGGGTCTGCTGAGTCCG-3'; reverse: 5'-ATCCATGGGGAGATGTTCTGG-3');

244 C/EBP-homologous protein (CHOP; forward: 5'-AGAACCAGGAAACGGAAACAGA-3';

245 reverse: 5'-TCTCCTTCATGCGCTGCTTT-3'); Actinin Alpha 1 (ACTN1; forward: 5'-

246 CCCGAGCTGATTGACTACGG-3'; reverse: 5'-GCAGTTCCAACGATGTCTTCG-3');

247 Actinin Alpha 2 (ACTN2; forward: 5'-GACATCGTGAACACCCCTAAAC-3'; reverse: 5'-

248 CCGCAAAAGCGTGGTAGAA); Actin Alpha 1 (ACTA1; forward: 5'-

249 TGCCAACAACGTCATGTCG-3'; reverse: 5'-CAGCGCGGTGATCTCTTTCT-3'); Troponin

250 I3, Cardiac Type (TNNI3; forward: 5'-TTTGACCTTCGAGGCAAGTTT-3'; reverse: 5'-

251 CCCGGTTTTCCTTCTCGGTG-3'); Troponin I1, Slow Skeletal Type (TNNT1; forward: 5'-

252 TGATCCCGCCAAAGATCCC-3'; reverse: 5'-TCTTCCGCTGCTCGAAATGTA-3'); Myosin

253 Heavy Chain 6 (MYH6; forward: 5'- GCCCTTTGACATTCGCACTG-3'; reverse: 5'-

254 GGTTTCAGCAATGACCTTGCC-3'); Myosin Heavy Chain 7 (MYH7; forward: 5'-

255 TCACCAACAACCCCTACGATT-3'; reverse: 5'- CTCCTCAGCGTCATCAATGGA-3'); and

$25610 \mathrm{ng}$ of cDNA per reaction. The reactions were performed on a StepOnePlus ${ }^{\mathrm{TM}}$ Real-Time PCR

257 System thermocycler (Applied Biosystems). The relative expression of the genes of interest

258 (GOI) was normalized by endogenous control genes: Glyceraldehyde-3-phosphate

259 Dehydrogenase (GAPDH; forward: 5'-GCCCTCAACGACCACTTTG-3'; reverse: 5'-

260 CCACCACCCTGTTGCTGTAG-3') and Hypoxanthine Phosphoribosyl transferase 1 (HPRT-1;

261 forward 5'-CGTCGTGATTAGTGATGATGAACC-3'; reverse: 5'-

262 AGAGGGCTACAATGTGATGGC-3').

263

264

265

Data analysis was performed with the $\mathrm{N}_{0}$ method implemented in LinRegPCR v. 2020.0 software, which considers efficiency estimated by the window-of-linearity method, as proposed

266

267

268 by Ramakers et al. (2003) and Ruijter et al. (2009) (Ramakers et al., 2003; Ruijter et al., 2009).

$\mathrm{N}_{0}$ values were calculated using default parameters and the arithmetic mean of $\mathrm{N}_{0}$ values from

269 GOI were normalized by taking its ratio to the $\mathrm{N}_{0}$ of the geometric mean of the endogenous control genes (REF) GAPDH and HRRT-1 $\left(\mathrm{N}_{0} \mathrm{GOI} / \mathrm{N}_{0} \mathrm{REF}\right)$.

270

271

Protein Expression

272 Media was completely removed from hiPSC-CMs, and $40 \mu \mathrm{L}$ of sample buffer without 273 bromophenol blue (62.5 mM Tris- $\mathrm{HCl}, \mathrm{pH} 6.8$, containing $10 \%$ glycerol, $2 \% \mathrm{SDS}$, and $5 \% 2$ -

274 mercaptoethanol) was added to each well. Next, cell extracts were boiled at $95^{\circ} \mathrm{C}$ for $5 \mathrm{~min}$,

275 centrifuged $16,000 \times \mathrm{g}$ for $15 \mathrm{~min}$ at $4^{\circ} \mathrm{C}$, and the supernatant was collected. Protein content was

276 estimated using the Bio-Rad Protein Assay (\#5000006, Bio-Rad). After the addition of

277 bromophenol blue (0.02\%), samples were separated by electrophoresis on an $8 \%$ SDS

278 polyacrylamide gel and transferred to polyvinylidene difluoride (PVDF) membranes. 
279 Western blotting was carried out with minor modification from the described (Towbin, Gordon

$280 \&$ Staehelin, 1989). Briefly, membranes were blocked in 5\% non-fat milk diluted in Tris-

281 Buffered Saline with 0.1\% Tween-20 (TBS-T) for $1 \mathrm{~h}$ at room temperature. Membranes were

282 then incubated overnight at $4^{\circ} \mathrm{C}$ with primary antibodies diluted in TBS-T with $5 \%$ non-fat milk.

283 Then, membranes were washed and incubated with peroxidase-conjugated antibodies. The

284 signals were developed using ECL Prime Western Blotting System (\#GERPN2232, Sigma) for 5

285 minutes and chemiluminescence was detected with an Odyssey-FC System ${ }^{\circledR \square}$ (LI-COR

286 Biosciences).

287

288

Stripping protocol was performed to break bonds between the antibodies and the transferred

289 proteins in order to reuse membranes. Briefly, membranes were incubated for three cycles of 10

290 minutes in a stripping buffer ( $\mathrm{pH} 2.2,200 \mathrm{mM}$ glycine, SDS $0.1 \%$ and $1 \%$ Tween-20). Then, the

291 buffer was discarded, the membranes were washed for 5 minutes with PBS and 5 minutes with

292

293 $0.1 \%$ TBS-T (three times each). Next, membranes were blocked again and proceeded with the above-described steps. Full-length membranes are displayed in Supplemental Figure 5.

294

295

Beating Frequency Evaluation

296 hiPSC-CMs were plated on 96-well plates $\left(1.8 \times 10^{4}\right.$ cells per well) and treated with NE-100 $1 \mu \mathrm{M}$

297 or vehicle (DMSO) before incubating at $37^{\circ} \mathrm{C}$. At $24-$ and 48 -hours post-treatment, beating

298 frequency was measured by manually counting the synchronous contractions of the monolayer

299 for 60 seconds (beats per minute). Cells were observed using an EVOS cell imaging system

300

301 (Thermo Fisher Scientific), in brightfield mode. Representative videos were recorded using Operetta ${ }^{\circledR}$ High-Content Screening System (Perkin Elmer) for each condition at baseline and 48

302 $h$ after treatment with vehicle or NE-100.

303

304

305

$\underline{\text { Statistical Analysis }}$

306

Data are presented as mean values, and error bars indicate the standard error of the mean

307 (S.E.M). Statistical differences were analyzed using nested t-test, unpaired two-tailed Welch's ttest and between three or more groups, unpaired multiple t-tests (Holm-Sidak method) or

308 ordinary one-way ANOVA with Holm-Sidak post-hoc. Prism v8.0 (GraphPad) was used for data analysis and graphics, where statistical significance was accepted at $\mathrm{P}<0.05$. The tests and $\mathrm{p}$

310 values are specified in figure legends and the symbols represent $\mathrm{p}<0.05,{ }^{*} \mathrm{p}<0.01,{ }^{*} \mathrm{p}<0.001$,

311 $* * * \mathrm{p}<0.0001$.

312

\section{Results}

314 Human induced pluripotent stem cell-derived cardiomyocytes (hiPSC-CMs) express the

315 Sigma-1 receptor (S1R)

316 Human cardiomyocytes were differentiated from induced pluripotent stem cells according to

317 established protocols (Cruvinel et al., 2020). Differentiation to cardiomyocytes resulted in low

318 expression of the pluripotency marker OCT-4 $(0.8 \% \pm 0.4 \%)$ and high expression of the specific 
322

323

324

325

326

327

328

329

330

331

332

333

334

335

336

337

338

339

340

341

342

343

344

345

346

347

348

349

350

351

352

353

354

355

356

357

358

cardiac muscle marker troponin $\mathrm{T}(\mathrm{cTnT})(88.4 \% \pm 8.4 \%)$ (Supplemental Figure $1 \mathrm{~A})$. The presence of cTnT was confirmed by immunostaining, as was cell morphology with F-actin staining (Supplemental Figure 1 B).

Previous studies showed that S1R was expressed in the human heart tissue and in atrial and ventricular cardiomyocytes of rodents (Novakova et al., 1995, 2010; Fagerberg et al., 2014; Abdullah et al., 2020). Here, we showed S1R mRNA and protein in hiPSC-CMs (Figure $1 \mathrm{~A}$ and $\mathrm{B}$, respectively). Immunostaining showed that $\mathrm{S} 1 \mathrm{R}$ is in the nuclei and in the perinuclear region of the cells (Figure 1 C). This is consistent with previous findings of the distribution of S1R in cells from rodents and yeasts and in human cell lines (Dussossoy et al., 1999; Hayashi \& Su, 2003a). S1R is enriched at the mitochondria-associated ER membrane (MAM) (Hayashi \& Su, 2007; Morales-Lázaro, González-Ramírez \& Rosenbaum, 2019). We found that part of cytosolic S1R staining was in close apposition with the mitochondrial marker VDAC1/Porin (Figure 1 D) and with the ER chaperone lectin Calnexin (CNX) (Figure 1 E) in hiPSC-CMs.

\section{Inhibition of S1R reduces infection and replication of SARS-CoV-2 and prevents cell death in human cardiomyocytes}

To test whether S1R had a direct influence on SARS-CoV-2 infection in human cardiomyocytes, the selective S1R antagonist, NE-100, was used to inhibit this receptor in hiPSC-CMs prior to exposure to the virus. NE-100 has a binding affinity for S1R within the nanomolar range and an IC50 200 times higher for other receptors, such as dopamine, serotonin, and phencyclidine receptors (Okuyama et al., 1993). Exposure of cardiomyocytes to NE-100 in the micromolar range for $24 \mathrm{~h}$ was reported to abolish the effects of a S1R agonist, similarly to what was observed using small interference RNA (siRNA) (Tagashira et al., 2013). Then, following $24 \mathrm{~h}$ exposure to $1 \mu \mathrm{M}$ NE-100, hiPSC-CMs were infected with SARS-CoV-2 at the multiplicity of infection (MOI) 0.1. Immunofluorescence using convalescent serum (CS) from a recovered COVID-19 patient showed that $57.3 \%( \pm 11.1 \%)$ of cells were infected at 48 h.p.i (hours postinfection) (Figure $2 \mathrm{~A}$ ). CS-staining was confirmed with co-localization with the specific SARSCoV-2 Spike Protein (SP) (Supplemental Figure 2).

Importantly, the inhibition of S1R reduced the percentage of infected hiPSC-CMs to $35.8 \%$ ( \pm $2.5 \%$ ) (Figure $2 \mathrm{~A}$ and B). Moreover, whereas infection of hiPSC-CMs with SARS-CoV-2 led to the production of infectious virions measured in the plaque assay, exposure to NE-100 considerably diminished this viral yield, with an average reduction of $82 \%$ plaque forming units (PFU) at 48 h.p.i (Figure $2 \mathrm{C}$ ). SARS-CoV-2 infection was previously shown to induce cytopathic features in hiPSC-CMs, mostly related to myofibrillar disruption, as described by other groups (Perez-Bermejo et al., 2021; Marchiano et al., 2021). Likewise, we detected a pattern of structural disarrangement of cardiac troponin T staining, as shown in Supplemental Figure 3. 
359

360

361

362

363

364

365

366

367

368

369

370

371

372

373

374

375

376

377

378

379

380

381

382

383

384

385

386

387

388

389

390

391

392

393

394

395

396

397

398

The release of lactate dehydrogenase (LDH) confirmed that SARS-CoV-2 caused cardiomyocyte death, as previously reported (Sharma et al., 2020). At 24, 48, and 72 h.p.i, LDH was elevated by 2.3, 5.6 and 2.7-fold, respectively, in SARS-CoV-2-infected cells when compared to controls (Figure 2 D). NE-100 was able to decrease the release of LDH at 48 h.p.i and also tended to decrease cytotoxicity at 72 h.p.i (Figure 2 D). There was no increase in the release of LDH when comparing uninfected to NE-100 treated controls (Figure $2 \mathrm{D}$ ). These results suggest that the inhibition of S1R does not induce cell death and may protect hiPSC-CMs by decreasing infection.

S1R is engaged in ER protein synthesis and acts as a chaperone for proteins translocating to cell surface (Vela, 2020). We investigated whether the inhibition of S1R could be related to modifications in the host cell receptor for viral entry, since it partially prevented the infection. The expression of the main viral entry receptor, ACE2, was measured after $24 \mathrm{~h}$ exposure to 1 $\mu \mathrm{M}$ NE-100. There was a reduction in the levels of ACE2 mRNA, albeit not statistically significant $(\mathrm{p}=0.0790)$ (Supplemental Figure 4 A). However, western blot analysis of ACE2 after NE-100 treatment did not show differences at the protein level (Supplemental Figure 4, B and C). These data suggest that the inhibition of SARS-CoV-2 infection in hiPSC-CMs can occur through mechanisms other than a reduction in the availability of ACE2 under the abovedescribed conditions.

\section{NE-100 attenuates cytokine release by SARS-CoV-2 infected hiPSC-CMs}

Cell death is the final denouement of hiPSC-CMs at 72 h.p.i (Sharma et al., 2020; Aragão et al., 2021). To investigate events before cell death, we analyzed some cytokines associated with COVID-19 at 24 and 48 h.p.i. This strategy was previously shown to be significant in the context of the infection of hiPSC-CMs by other pathogens that target the heart (Bozzi et al., 2019).

SARS-CoV-2 infection increased the release of interleukin (IL)- 6 when compared to control. NE-100 decreased this response at 24 h.p.i and 48 h.p.i (Figure 3 A and 3 B). Conversely, no differences in the secretion of IL-8 were observed at 24 h.p.i (Figure 3 A), however, at 48 h.p.i, SARS-CoV-2 increased IL- 8 by 5.5 -fold relative to the mock condition (Figure $3 \mathrm{~B}$ ).

Comparably to the modulation of IL-6, NE-100 decreased the secretion of IL-8 (Figure 3 B). Tumor necrosis factor-alpha (TNF- $\alpha$ ) levels were only transiently increased at 24 h.p.i (3.3-fold) but were nevertheless inhibited by previous NE-100 treatment (Figure 3 and B).

\section{S1R inhibition decreases beating in cardiomyocytes}

To investigate the consequences of the inhibition of S1R in human cardiomyocytes by itself, we conducted further tests on the effects of NE-100 in hiPSC-CMs. We first analyzed whether NE100 induces cell death. NE-100 does not decrease cell viability after $72 \mathrm{~h}$ at concentrations ranging from $10 \mathrm{nM}$ to $10 \mu \mathrm{M}$ as measured by the neutral red assay (Figure $4 \mathrm{~A}$ ). Also, hiPSCCMs treated with $1 \mu \mathrm{M}$ NE-100 for 48 h showed no changes in the number of pyknotic nuclei, 
399

400

401

402

403

404

405

406

407

408

409

410

411

412

413

414

415

416

417

418

419

420

421

422

423

424

425

426

427

428

429

430

431

432

433

434

435

436

437

which represents an irreversible chromatin-condensed nuclear state characteristic of cell death (Figure 4 B).

Furthermore, given that S1R function is important for the ER stress response, we investigated whether NE-100 modulates the endonuclease activity of inositol-requiring enzyme $1 \alpha$ (IRE1 $\alpha$ ) by analysis of splicing of XBP1 mRNA, measuring the levels of spliced XBP1 mRNA (sXBP1), in addition to the unspliced (uXBP1) and total XBP1 mRNAs (Oslowski \& Urano, 2011). We found low levels of sXBP1 mRNA and high levels of uXBP1 mRNA in hiPSC-CMs which are consistent with cells under non-ER stress condition (Figure $4 \mathrm{C}$ ). NE-100 treatment did not affect levels of sXBP1 or uXBP1 mRNAs/total XBP1 (Figure $4 \mathrm{C}$ ). These results indicate that NE-100 did not induce activation of IRE1 $\alpha$ in hiPSC-CMs under these conditions. Another indicator of ER stress response is the upregulation of the C/EBP-homologous protein (CHOP or GADD153). Again, we did not find changes in CHOP mRNA after NE-100 treatment (Figure 4 D).

These data suggest that NE-100 does not induce hiPSC-CMs death or ER stress response in the absence of additional stressor stimuli. However, one of the main functional features displayed by cultured cardiomyocytes is their ability to perform spontaneous contractions. In that matter, hiPSC-CMs are suitable to evaluate drug-induced changes in contractility (Pointon et al., 2015; Niehoff et al., 2019). We observed a decrease from $17.7( \pm 5.9)$ beats per minute $(\mathrm{bpm})$ to 6.7 ( \pm $1.8) \mathrm{bpm}$ and from $14.7( \pm 2.8) \mathrm{bpm}$ to $4.1( \pm 0.8) \mathrm{bpm}$ after $24 \mathrm{~h}$ and $48 \mathrm{~h}$ of NE-100 exposure, respectively (Figure $4 \mathrm{E}$ and Supplemental Videos S1-S4). These results suggest that the inhibition of S1R leads to changes in beating rate and a putative deviation in contractility.

\section{The S1R antagonist NE-100 induces maladaptive transcriptional and structural changes in human cardiomyocytes}

The findings on the decremental impact of NE-100 on the cardiomyocytes beating rate led us to pursue this issue further. S1R plays a cardioprotective role during maladaptive cardiac remodeling and the anti-hypertrophic properties of S1R agonists have been described (Tagashira \& Fukunaga, 2012; Tagashira et al., 2013; Hirano, Tagashira \& Fukunaga, 2014). Therefore, we also investigated if the S1R antagonist NE-100 alone could induce a hypertrophic response. To that end, we quantified the expression of key genes upon S1R inhibition. First, by measuring mRNA levels of the atrial natriuretic peptide (ANP), which is one of the main transcripts of the fetal program for cardiac growth. ANP overexpression is frequently correlated to cardiac hypertrophy but NE-100 decreased ANP mRNA expression by 1.49-fold after $24 \mathrm{~h}$ (Figure 5 A). There was also no increase in the average cell surface area of hiPSC-CMs observed by F-actin staining. In fact, more like the contrary, NE-100 exposure caused a decrease in the average cell surface area after $48 \mathrm{~h}$ (Figure $5 \mathrm{~B}$ ), which is a phenotype opposite to the expected for cardiomyocyte hypertrophic responses in vitro (Watkins et al., 2012). 
438 After observing cell shrinking in longer exposures to NE-100, we then hypothesized that S1R 439 inhibition could be triggering morphological changes. Hence, we investigated the expression of 440 myofibril-associated genes important for cytoarchitecture maintenance and observed a 441 downregulation of 4 out of 7 genes investigated. The decreased expression of ACTN2 (- 1.53442 fold), ACTA1 (- 11.1-fold), TNNI3 (- 2.32-fold) and TNNT1 (- 2.43-fold) after the inhibition of 443 S1R suggests a transcriptional regulation that could impair sarcomeric organization and 444 cardiomyocyte cytoskeletal integrity (Figure $5 \mathrm{C}$ ). ACTN1 and $M Y H 7$ expression did not show 445 significant changes upon NE-100 exposure (Figure 5 C). Interestingly, MYH7 upregulation is 446 highly associated with hypertrophy (Krenz \& Robbins, 2004; Gupta, 2007). Therefore, this result 447 corroborates the assumption that the inhibition of S1R in the absence of a hypertrophic stimulus 448 is not sufficient to activate the molecular profile of cardiac hypertrophy in hiPSC-CMs (i.e., ANP 449 and $M Y H 7$ upregulation). Intriguingly, MYH6 was the only transcript upregulated by 3.44-fold 450 451

452 453 454 455 456 457 458 459 460 461

462

463

464

465

466

467

468

469

470

471

472

473

474

475

476 $(\mathrm{p}=0.0502)$ (Figure $5 \mathrm{C})$, which could represent a transcriptional compensatory adaptation.

Furthermore, cardiac troponin $\mathrm{T}(\mathrm{cTnT})$ staining analysis revealed a significant decrease both in immunoreactive area and fluorescence intensity on hiPSC-CMs exposed to NE-100 when compared to untreated controls (Figure $5 \mathrm{D}$ and $\mathrm{E}$, respectively). These results are probably attributable also to a decrease in cellular cTnT content rather than exclusively to a change in the cell area, indicating a considerable loss of troponin. Consistently, the morphology of cytoskeletal fibers was grossly affected after $48 \mathrm{~h}$, as shown in confocal fluorescence images (Figure $5 \mathrm{~F}$ ). Taken together, our results suggest that S1R inhibition caused neither change in cell viability nor induction of hypertrophy parameters. However, despite this apparent lack of negative effects related to cell death and hypertrophy, there was a downregulation of genes encoding structural proteins and cytoskeletal impairment via a decrease in cardiac troponin $\mathrm{T}$ content. The latter significant effects could explain in part the beating frequency reduction of human cardiomyocytes exposed to NE-100.

\section{Discussion}

In this study, we show that hiPSC-CMs are permissive to productive infection of SARS-CoV-2, corroborating previous reports (Bulfamante et al., 2020; Sharma et al., 2020; Choi et al., 2020; Bojkova et al., 2020; Bailey et al., 2021; Perez-Bermejo et al., 2021; Marchiano et al., 2021). Although the presence of SARS-CoV-2 in the postmortem heart is still controversial, the cytopathic features following cardiomyocyte infection in vitro are similar to those observed in the cardiac tissue of patients deceased from COVID-19, including sarcomeric fragmentation, innate immune cells activation and cell death (Lindner et al., 2020; Bailey et al., 2021; PerezBermejo et al., 2021). Here, we confirmed that SARS-CoV-2 induces cardiotoxicity by directly infecting cardiomyocytes. 
477 Aside from viral infection and replication, immune responses are a hallmark of COVID-19

478 pathology that can also be modeled using hiPSC-CMs (Azkur et al., 2020; Dariolli et al., 2021).

479 Along with monocytes and fibroblasts, cardiomyocytes are considered an important source of

480 cytokines during events such as heart failure (Aoyagi \& Matsui, 2012). In fact, Wong and

481 collaborators have shown that SARS-CoV-2 upregulates the expression of pro-inflammatory

482 cytokines in hiPSC-CMs, including IL-6, IL-8, and TNF- $\alpha$ (Wong et al., 2020). Here, we

483 confirmed the release of cytokines after the infection with SARS-CoV-2. Elevated levels of IL-6

484 are correlated with cardiac damage and heart failure in rodent models (Janssen et al., 2005).

485 Moreover, previous reports demonstrated that IL-6 produced by cardiomyocytes promotes

486 inflammation in the heart by recruiting neutrophils (Youker et al., 1992). Interestingly, IL-8,

487 which was also increased, is a neutrophil chemotactic factor correlated with heart disease

488 (Rothenbacher et al., 2006; Akasaka et al., 2006). Myocardial infiltration of neutrophils has been

489 reported in the hearts of COVID-19 patients and is associated with myocardial damage (Yao et

490 al., 2020).

491

492

493

494

495

496

497

498

499

Nonetheless, the characterization of the interlinkage between the virus and intracellular structures may provide therapeutic clues against COVID-19. A SARS-CoV-2-human protein interaction map showed that NSP6 interacts directly with S1R (Gordon et al., 2020b). The antiviral activity of sigma receptor ligands was described in Vero E6 cells (Gordon et al., 2020b). S1R knockdown in A549 cells and S1R knockout in Caco-2 cells further confirmed S1R, but not Sigma-2 receptor, as a host-dependency factor for SARS-CoV-2 infection (Gordon et al., 2020a). NSP6 orchestrates vesicle trafficking and regulates ER remodeling during the replication of

500 mammalian coronaviruses (Cottam et al., 2011b) and its interaction with S1R possibly

501

502

503

504

505

506

507

508

509

510

511 The inhibition of S1R with NE-100 reduced the number of infected cells, the replication of

512 SARS-CoV-2, prevented infection-associated cell death and attenuated the release of cytokines.

513 However, it is the activation of S1R that has been described with anti-inflammatory properties

514 (Szabo et al., 2014; Rosen et al., 2019; Zhou et al., 2019). It was recently reported that the S1R

515 agonist fluvoxamine prevents clinical deterioration of symptomatic COVID-19 and the

516 persistence of residual symptoms (Lenze et al., 2020; Seftel \& Boulware, 2021). Consequently, 
517 the reduction of pro-inflammatory cytokines described here is more likely due to the inhibition of

518 infection rather than a direct suppression of the release of cytokines.

519

520

Although S1R is foregrounded in COVID-19 research, it is currently unclear if a S1R antagonist

521 or agonist could be better to treat the disease, since in vitro reports show that S1R antagonists

522 prevent SARS-CoV-2 replication and S1R agonists have proviral activity, while clinical

523 evidence suggests that S1R agonists prevent worsening of symptoms. In spite of that, evidence of

524 side effects of S1R ligands, especially cardiac-specific detrimental cellular effects, are

525 overlooked in current studies and should be acknowledged for further treatment options. In order

526 to look into the consequences of S1R inhibition per se on hiPSC-CMs, other aspects were

527 investigated beyond antiviral activity. The survival of cardiomyocytes was not affected by NE100. Given the role of S1R in ER stress response, the mRNA levels of sXBP1 and CHOP were

529 investigated as another aspect of toxicity (Wang et al., 2018). The spliced XBP1 analysis represents a reliable indirect method to determine IRE1 $\alpha$ activation, which is one of the major ER stress sensors involved in pro-inflammatory cytokine production (Oslowski \& Urano, 2011; Rosen et al., 2019).

533

534

Alam and collaborators' have demonstrated that the knockdown of S1R increases the expression of CHOP in neonatal rat ventricular cardiomyocytes, while decreases spliced XBP1 with tunicamycin (Alam et al., 2017). It means that S1R is crucial for coping with ER stress and that its depletion favors cytotoxic ER stress response in cardiac cells by CHOP upregulation and impaired sXBP1-mediated signaling. In the present study, no changes in the transcript levels of sXBP1 and CHOP were detected in hiPSC-CMs with NE-100. Our results suggest that there is no intrinsic ER stress induction by NE-100, but future studies should explore the role of S1R ligands in ER stress transcripts' expression upon ER-stressor stimuli in hiPSC-CMs.

542

543

Nonetheless, we observed that inhibition of S1R reduced the frequency of cardiomyocytes' beating. Consistent with our findings, it has been noted that S1R antagonists cause delayed cardiac repolarization, impairment of rate adaptation, and increased risk for drug-induced arrhythmia (Witchel, 2011; Balasuriya et al., 2014; Morales-Lázaro, González-Ramírez \&

548 of SARS-CoV-2 (Gordon et al., 2020b,a). However, this antipsychotic did not decrease the risk

549 for intubation or death in hospitalized patients (Hoertel et al., 2021). The anti-SARS-CoV-2

550 activity of the broad-spectrum antiviral remdesivir was described in human cardiomyocytes by

551 Choi and colleagues, together with a safety profile evaluation that stipulated considerable

552 arrhythmogenic and cardiotoxic risk in vitro. These results, raised concerns regarding the drug-

553 induced cardiotoxicity of repositioned pre-approved compounds to manage COVID-19 (Choi et

554 al., 2020). The contractile capacity of cardiomyocytes is related to calcium availability. Since

$555 \mathrm{~S} 1 \mathrm{R}$ is a key regulator of intracellular calcium homeostasis, the possibility that blocking its

556 function may hamper the availability of cytoplasmic calcium and decrease beating rate in hiPSC- 
557 CMs should be considered. Indeed, previous studies showed an interconnection among S1R and

558

559

560

561

562

563

564

565

566

567

568

569

570

571

572

573

574

575

576

577

578

579

580

581

582

583

584

585

586

587

588

589

590

591

592

593

594

595

596

mitochondrial function, calcium handling and contractility (Ela et al., 1994; Tarabová, Nováková \& Lacinová, 2009). Although there is abundant data on S1R-dependent modulation of calcium homeostasis, ER stress response and hypertrophy (Bhuiyan \& Fukunaga, 2009; Tagashira \& Fukunaga, 2012; Tagashira et al., 2013), no previous study explored the consequences of the inhibition of S1R in the integrity of human cardiomyocytes' cytoskeleton.

S1R is a direct target of methamphetamine (Nguyen et al., 2005). Heart tissue from S1R knockout mice and autopsy samples of human methamphetamine users present fibrosis and signs of contractile dysfunction, suggesting a correlation between S1R and heart tissue remodeling (Abdullah et al., 2018, 2020). Although S1R activation is known to protect cardiomyocytes from hypertrophy upon pressure-overload, in the present study exposure of hiPSC-CMs to NE-100 with no secondary hypertrophic stimulus was not sufficient to neither increase the expression of $A N P$ and $M Y H 7$ nor cellular size.

The association between S1R and sarcomeric integrity was hypothesized (Alam et al., 2017), but morphological changes in human cardiomyocytes following S1R inhibition were not explored. Herein, S1R inhibition compromised the morphology of hiPSC-CMs with a perturbation of cytoskeletal architecture. The changes in morphology were accompanied by a decrease in cardiac troponin $\mathrm{T}$ and preceded by a downregulation of genes encoding key cytoskeletal proteins in cytoarchitecture maintenance, such as $\alpha$-actinin 2 , actin- $\alpha 1$, troponin I3 and troponin T1. Importantly, the downregulation of these genes is associated with cardiotoxicity induced by doxorubicin, daunorubicin and mitoxantrone (Chaudhari et al., 2016). Out of seven targets investigated, MYH6 was the only transcript increased with NE-100. It was previously demonstrated that the expression of myosin heavy chain is specifically induced as a compensatory response following disruption of the myofibrillar structure in hiPSC-CMs (PerezBermejo et al., 2021). Future studies should elucidate the mechanisms behind cytoskeletal changes and cardiomyocyte recovery after inhibition of S1R.

\section{Conclusions}

The disruption of cytoskeletal and sarcomeric proteins by a decrease in expression or anomalous arrangement could underlie cardiomyopathies and heart failure, representing a potential mechanism by which drugs inhibiting S1R jeopardize cardiac integrity and contractility (Sequeira et al., 2014). Our results suggest that the inhibition of S1R leads to morphological and transcriptional changes in human cardiac cells and, therefore, its use as a therapeutic strategy against COVID-19 should be further investigated before translated to clinical application, due to the concern of drug-induced cardiac damage and malfunction.

Peer) reviewing PDF | (2021:09:66092:1:0:NEW 10 Nov 2021) 


\section{Acknowledgements}

598 We thank Professor Leticia Raposo for the support in the statistical analysis of the data presented

599

600

603

603

606

607

608

609

610

611

612

613

614

615

616

617

618

619

620

621

622

623

624

625

626

627

628

629

630

631

632

633

634

635

636

637

638

639

640

641

642

643

644 in this manuscript. We also thank Emiliano Horacio Medei and Renata Junqueira Moll Bernardes for scientific discussions. This work was at the Morphological Sciences Program, University of Rio de Janeiro (UFRJ), Rio developed as part of the doctoral thesis of J.A.S. Biomedical Sciences Institute, Federal de Janeiro, Brazil.

\section{References}

Abdullah CS, Aishwarya R, Alam S, Morshed M, Remex NS, Nitu S, Kolluru GK, Traylor J, Miriyala S, Panchatcharam M, Hartman B, King J, Bhuiyan MAN, Chandran S, Woolard MD, Yu X, Goeders NE, Dominic P, Arnold CL, Stokes K, Kevil CG, Orr AW, Bhuiyan MS. 2020. Methamphetamine induces cardiomyopathy by Sigmar1 inhibition-dependent impairment of mitochondrial dynamics and function. Communications Biology 2020 3:1 3:1-20. DOI: 10.1038/s42003-020-01408-z.

Abdullah CS, Alam S, Aishwarya R, Miriyala S, Panchatcharam M, Bhuiyan MAN, Peretik JM, Orr AW, James J, Osinska H, Robbins J, Lorenz JN, Bhuiyan MS. 2018. Cardiac Dysfunction in the Sigma 1 Receptor Knockout Mouse Associated With Impaired Mitochondrial Dynamics and Bioenergetics. Journal of the American Heart Association 7. DOI: 10.1161/JAHA.118.009775.

Akasaka Y, Morimoto N, Ishikawa Y, Fujita K, Ito K, Kimura-Matsumoto M, Ishiguro S, Morita H, Kobayashi Y, Ishii T. 2006. Myocardial apoptosis associated with the expression of proinflammatory cytokines during the course of myocardial infarction. Modern Pathology 19:588-598. DOI: 10.1038/modpathol.3800568.

Alam S, Abdullah CS, Aishwarya R, Orr AW, Traylor J, Miriyala S, Panchatcharam M, Pattillo CB, Bhuiyan MS. 2017. Sigmar1 regulates endoplasmic reticulum stress-induced C/EBPhomologous protein expression in cardiomyocytes. Bioscience Reports 37:20170898. DOI: 10.1042/BSR20170898.

Aoyagi T, Matsui T. 2012. The Cardiomyocyte as a Source of Cytokines in Cardiac Injury. Journal of Cell Science \& Therapy s5. DOI: 10.4172/2157-7013.s5-003.

Aragão LGHS, Oliveira JT, Temerozo JR, Mendes MA, Salerno JA, Pedrosa CSG, Puig-Pijuan T, Veríssimo CP, Ornelas IM, Torquato T, Vitória G, Sacramento CQ, Fintelman-Rodrigues N, Da Silva Gomes Dias S, Soares VC, Souza LRQ, Karmirian K, Goto-Silva L, Biagi D, Cruvinel EM, Dariolli R, Furtado DR, Bozza PT, Borges HL, Souza TML, Guimarães MZP, Rehen SK. 2021. WIN 55,212-2 shows anti-inflammatory and survival properties in human iPSC-derived cardiomyocytes infected with SARS-CoV-2. PeerJ 9. DOI: 10.7717/peerj.12262.

Azkur AK, Akdis M, Azkur D, Sokolowska M, van de Veen W, Brüggen MC, O’Mahony L, Gao Y, Nadeau K, Akdis CA. 2020. Immune response to SARS-CoV-2 and mechanisms of immunopathological changes in COVID-19. Allergy: European Journal of Allergy and Clinical Immunology 75:1564-1581. DOI: 10.1111/all.14364.

Bailey AL, Dmytrenko O, Greenberg L, Bredemeyer AL, Ma P, Liu J, Penna V, Winkler ES, Sviben S, Brooks E, Nair AP, Heck KA, Rali AS, Simpson L, Saririan M, Hobohm D, Stump WT, Fitzpatrick JA, Xie X, Zhang X, Shi P-Y, Hinson JT, Gi W-T, Schmidt C, Leuschner F, Lin C-Y, Diamond MS, Greenberg MJ, Lavine KJ. 2021. SARS-CoV-2 Infects Human Engineered Heart Tissues and Models COVID-19 Myocarditis. JACC: Basic 
645

646

647

648

649

650

651

652

653

654

655

656

657

658

659

660

661

662

663

664

665

666

667

668

669

670

671

672

673

674

675

676

677

678

679

680

681

682

683

684

685

686

687

688

689

690

to Translational Science. DOI: 10.1016/j.jacbts.2021.01.002.

Balasuriya D, D’Sa L, Talker R, Dupuis E, Maurin F, Martin P, Borgese F, Soriani O, Edwardson JM. 2014. A direct interaction between the sigma-1 receptor and the herg voltage-gated $\mathrm{K}+$ channel revealed by atomic force microscopy and homogeneous timeresolved fluorescence (HTRF®). Journal of Biological Chemistry 289:32353-32363. DOI: 10.1074/jbc.M114.603506.

Bhuiyan MS, Fukunaga K. 2009. Stimulation of Sigma-1 receptor signaling by dehydroepiandrosterone ameliorates pressure overload-induced hypertrophy and dysfunctions in ovariectomized rats. Expert Opinion on Therapeutic Targets 13:1253-1265. DOI: $10.1517 / 14728220903264064$.

Bojkova D, Wagner JUG, Shumliakivska M, Aslan GS, Saleem U, Hansen A, Luxán G, Günther S, Pham MD, Krishnan J, Harter PN, Ermel UH, Frangakis AS, Milting H, Zeiher AM, Klingel K, Cinatl J, Dendorfer A, Eschenhagen T, Tschöpe C, Ciesek S, Dimmeler S. 2020. SARS-CoV-2 infects and induces cytotoxic effects in human cardiomyocytes. Cardiovascular research 116:2207-2215. DOI: 10.1093/cvr/cvaa267.

Bozzi A, Sayed N, Matsa E, Sass G, Neofytou E, Clemons K, Correa-Oliveira R, Stevens D, Wu J. 2019. Using Human Induced Pluripotent Stem Cell-Derived Cardiomyocytes as a Model to Study Trypanosoma cruzi Infection. Stem cell reports 12:1232-1241. DOI: 10.1016/J.STEMCR.2019.04.017.

Brune S, Pricl S, Wünsch B. 2013. Structure of the $\sigma 1$ receptor and its ligand binding site. Journal of Medicinal Chemistry 56:9809-9819. DOI: 10.1021/jm400660u.

Bulfamante G Pietro, Perrucci GL, Falleni M, Sommariva E, Tosi D, Martinelli C, Songia P, Poggio P, Carugo S, Pompilio G. 2020. Evidence of sars-cov-2 transcriptional activity in cardiomyocytes of covid-19 patients without clinical signs of cardiac involvement. Biomedicines 8:1-13. DOI: 10.3390/biomedicines8120626.

Chaudhari U, Nemade H, Wagh V, Gaspar JA, Ellis JK, Srinivasan SP, Spitkovski D, Nguemo F, Louisse J, Bremer S, Hescheler J, Keun HC, Hengstler JG, Sachinidis A. 2016. Identification of genomic biomarkers for anthracycline-induced cardiotoxicity in human iPSC-derived cardiomyocytes: an in vitro repeated exposure toxicity approach for safety assessment. Archives of Toxicology 90:2763-2777. DOI: 10.1007/s00204-015-1623-5.

Chen CY, Wang FL, Lin CC. 2006. Chronic hydroxychloroquine use associated with QT prolongation and refractory ventricular arrhythmia. Clinical Toxicology 44:173-175. DOI: $10.1080 / 15563650500514558$.

Choi SW, Shin JS, Park S-J, Jung E, Park Y-G, Lee J, Kim SJ, Park H-J, Lee J-H, Park S-M, Moon S-H, Ban K, Go YY. 2020. Antiviral activity and safety of remdesivir against SARSCoV-2 infection in human pluripotent stem cell-derived cardiomyocytes. Antiviral Research:104955. DOI: 10.1016/j.antiviral.2020.104955.

Cottam EM, Maier HJ, Manifava M, Vaux LC, Chandra-Schoenfelder P, Gerner W, Britton P, Ktistakis NT, Wileman T. 2011a. Coronavirus nsp6 proteins generate autophagosomes from the endoplasmic reticulum via an omegasome intermediate. Autophagy 7:1335-1347. DOI: 10.4161/auto.7.11.16642.

Cottam EM, Maier HJ, Manifava M, Vaux LC, Chandra-Schoenfelder P, Gerner W, Britton P, Ktistakis NT, Wileman T. 2011b. Coronavirus nsp6 proteins generate autophagosomes from the endoplasmic reticulum via an omegasome intermediate. Autophagy 7:1335-1347. DOI: 10.4161/auto.7.11.16642.

Cottam E, Whelband M, Wileman T. 2014. Coronavirus NSP6 restricts autophagosome

Peer] reviewing PDF | (2021:09:66092:1:0:NEW 10 Nov 2021) 
expansion. Autophagy 10:1426-1441. DOI: 10.4161/AUTO.29309.

Cruvinel E, Ogusuku I, Cerioni R, Rodrigues S, Gonçalves J, Góes ME, Alvim JM, Silva AC, Lino V de S, Boccardo E, Goulart E, Pereira A, Dariolli R, Valadares M, Biagi D. 2020. Long-term single-cell passaging of human iPSC fully supports pluripotency and highefficient trilineage differentiation capacity. SAGE Open Medicine 8:205031212096645. DOI: $10.1177 / 2050312120966456$.

Dariolli R, Campana C, Gutierrez A, Sobie EA. 2021. In vitro and in silico models to study SARS-CoV-2 infection: integrating experimental and computational tools to mimic \&quot;COVID-19 cardiomyocyte\&quot; Frontiers in Physiology 12:119. DOI: 10.3389/FPHYS.2021.624185.

Dussossoy D, Carayon P, Belugou S, Feraut D, Bord A, Goubet C, Roque C, Vidal H, Combes T, Loison G, Casellas P. 1999. Colocalization of sterol isomerase and sigma(1) receptor at endoplasmic reticulum and nuclear envelope level. European journal of biochemistry 263:377-386. DOI: 10.1046/J.1432-1327.1999.00500.X.

Ela C, Barg J, Vogel Z, Hasin Y, Eilam Y. 1994. Sigma receptor ligands modulate contractility, $\mathrm{Ca}++$ influx and beating rate in cultured cardiac myocytes. Journal of Pharmacology and Experimental Therapeutics 269:1300-1309.

Fagerberg L, Hallstrom BM, Oksvold P, Kampf C, Djureinovic D, Odeberg J, Habuka M, Tahmasebpoor S, Danielsson A, Edlund K, Asplund A, Sjostedt E, Lundberg E, Szigyarto CAK, Skogs M, Ottosson Takanen J, Berling H, Tegel H, Mulder J, Nilsson P, Schwenk JM, Lindskog C, Danielsson F, Mardinoglu A, Sivertsson A, Von Feilitzen K, Forsberg M, Zwahlen M, Olsson I, Navani S, Huss M, Nielsen J, Ponten F, Uhlen M. 2014. Analysis of the human tissue-specific expression by genome-wide integration of transcriptomics and antibody-based proteomics. Molecular and Cellular Proteomics 13:397-406. DOI: 10.1074/mcp.M113.035600.

Friesland M, Mingorance L, Chung J, Chisari F V., Gastaminza P. 2013. Sigma-1 Receptor Regulates Early Steps of Viral RNA Replication at the Onset of Hepatitis C Virus Infection. Journal of Virology 87:6377-6390. DOI: 10.1128/jvi.03557-12.

Gnecchi M, Moretti F, Bassi EM, Leonardi S, Totaro R, Perotti L, Zuccaro V, Perlini S, Preda L, Baldanti F, Bruno R, Visconti LO. 2020. Myocarditis in a 16-year-old boy positive for SARS-CoV-2. The Lancet 395:e116. DOI: 10.1016/S0140-6736(20)31307-6.

Gordon DE, Hiatt J, Bouhaddou M, Rezelj V V., Ulferts S, Braberg H, Jureka AS, Obernier K, Guo JZ, Batra J, Kaake RM, Weckstein AR, Owens TW, Gupta M, Pourmal S, Titus EW, Cakir M, Soucheray M, McGregor M, Cakir Z, Jang G, O’Meara MJ, Tummino TA, Zhang Z, Foussard H, Rojc A, Zhou Y, Kuchenov D, Hüttenhain R, Xu J, Eckhardt M, Swaney DL, Fabius JM, Ummadi M, Tutuncuoglu B, Rathore U, Modak M, Haas P, Haas KM, Naing ZZC, Pulido EH, Shi Y, Barrio-Hernandez I, Memon D, Petsalaki E, Dunham A, Marrero MC, Burke D, Koh C, Vallet T, Silvas JA, Azumaya CM, Billesbølle C, Brilot AF, Campbell MG, Diallo A, Dickinson MS, Diwanji D, Herrera N, Hoppe N, Kratochvil HT, Liu Y, Merz GE, Moritz M, Nguyen HC, Nowotny C, Puchades C, Rizo AN, SchulzeGahmen U, Smith AM, Sun M, Young ID, Zhao J, Asarnow D, Biel J, Bowen A, Braxton JR, Chen J, Chio CM, Chio US, Deshpande I, Doan L, Faust B, Flores S, Jin M, Kim K, Lam VL, Li F, Li J, Li YL, Li Y, Liu X, Lo M, Lopez KE, Melo AA, Moss FR, Nguyen P, Paulino J, Pawar KI, Peters JK, Pospiech TH, Safari M, Sangwan S, Schaefer K, Thomas P V., Thwin AC, Trenker R, Tse E, Tsui TKM, Wang F, Whitis N, Yu Z, Zhang K, Zhang Y, Zhou F, Saltzberg D, Hodder AJ, Shun-Shion AS, Williams DM, White KM, Rosales R, 
760

761

762

763

764

765

766

767

768

769

770

771

772

773

774

775

776

777

778

779

780

781

782

Kehrer T, Miorin L, Moreno E, Patel AH, Rihn S, Khalid MM, Vallejo-Gracia A, Fozouni P, Simoneau CR, Roth TL, Wu D, Karim MA, Ghoussaini M, Dunham I, Berardi F, Weigang S, Chazal M, Park J, Logue J, McGrath M, Weston S, Haupt R, Hastie CJ, Elliott M, Brown F, Burness KA, Reid E, Dorward M, Johnson C, Wilkinson SG, Geyer A, Giesel DM, Baillie C, Raggett S, Leech H, Toth R, Goodman N, Keough KC, Lind AL, Klesh RJ, Hemphill KR, Carlson-Stevermer J, Oki J, Holden K, Maures T, Pollard KS, Sali A, Agard DA, Cheng Y, Fraser JS, Frost A, Jura N, Kortemme T, Manglik A, Southworth DR, Stroud RM, Alessi DR, Davies P, Frieman MB, Ideker T, Abate C, Jouvenet N, Kochs G, Shoichet B, Ott M, Palmarini M, Shokat KM, García-Sastre A, Rassen JA, Grosse R, Rosenberg OS, Verba KA, Basler CF, Vignuzzi M, Peden AA, Beltrao P, Krogan NJ. 2020a. Comparative host-coronavirus protein interaction networks reveal pan-viral disease mechanisms. Science 370. DOI: $10.1126 /$ science.abe 9403 .

Gordon DE, Jang GM, Bouhaddou M, Xu J, Obernier K, White KM, O’Meara MJ, Rezelj V V., Guo JZ, Swaney DL, Tummino TA, Hüttenhain R, Kaake RM, Richards AL, Tutuncuoglu B, Foussard H, Batra J, Haas K, Modak M, Kim M, Haas P, Polacco BJ, Braberg H, Fabius JM, Eckhardt M, Soucheray M, Bennett MJ, Cakir M, McGregor MJ, Li Q, Meyer B, Roesch F, Vallet T, Mac Kain A, Miorin L, Moreno E, Naing ZZC, Zhou Y, Peng S, Shi Y, Zhang Z, Shen W, Kirby IT, Melnyk JE, Chorba JS, Lou K, Dai SA, Barrio-Hernandez I, Memon D, Hernandez-Armenta C, Lyu J, Mathy CJP, Perica T, Pilla KB, Ganesan SJ, Saltzberg DJ, Rakesh R, Liu X, Rosenthal SB, Calviello L, Venkataramanan S, Liboy-Lugo J, Lin Y, Huang XP, Liu YF, Wankowicz SA, Bohn M, Safari M, Ugur FS, Koh C, Savar NS, Tran QD, Shengjuler D, Fletcher SJ, O’Neal MC, Cai Y, Chang JCJ, Broadhurst DJ, Klippsten S, Sharp PP, Wenzell NA, Kuzuoglu-Ozturk D, Wang HY, Trenker R, Young JM, Cavero DA, Hiatt J, Roth TL, Rathore U, Subramanian A, Noack J, Hubert M, Stroud RM, Frankel AD, Rosenberg OS, Verba KA, Agard DA, Ott M, Emerman M, Jura N, von Zastrow M, Verdin E, Ashworth A, Schwartz O, d'Enfert C, Mukherjee S, Jacobson M, Malik HS, Fujimori DG, Ideker T, Craik CS, Floor SN, Fraser JS, Gross JD, Sali A, Roth BL, Ruggero D, Taunton J, Kortemme T, Beltrao P, Vignuzzi M, García-Sastre A, Shokat KM, Shoichet BK, Krogan NJ. 2020b. A SARS-CoV-2 protein interaction map reveals targets for drug repurposing. Nature 583:459-468. DOI: 10.1038/s41586-020-2286-9.

Gupta MP. 2007. Factors controlling cardiac myosin-isoform shift during hypertrophy and heart failure. Journal of molecular and cellular cardiology 43:388. DOI: 10.1016/J.YJMCC.2007.07.045.

Hashimoto K. 2021. Repurposing of CNS drugs to treat COVID-19 infection: targeting the sigma-1 receptor. European Archives of Psychiatry and Clinical Neuroscience 271:249258. DOI: 10.1007/s00406-020-01231-x.

Hayashi T. 2015. Sigma-1 receptor: The novel intracellular target of neuropsychotherapeutic drugs. Journal of Pharmacological Sciences 127:2-5. DOI: 10.1016/j.jphs.2014.07.001. Hayashi T, Rizzuto R, Hajnoczky G, Su TP. 2009. MAM: more than just a housekeeper. Trends in Cell Biology 19:81-88. DOI: 10.1016/j.tcb.2008.12.002.

Hayashi T, Su TP. 2003a. $\sigma-1$ receptors ( $\sigma 1$ binding sites) form raft-like microdomains and target lipid droplets on the endoplasmic reticulum: Roles in endoplasmic reticulum lipid compartmentalization and export. Journal of Pharmacology and Experimental Therapeutics 306:718-725. DOI: 10.1124/jpet.103.051284.

Hayashi T, Su TP. 2003b. $\sigma-1$ receptors ( $\sigma 1$ binding sites) form raft-like microdomains and target lipid droplets on the endoplasmic reticulum: Roles in endoplasmic reticulum lipid 
783

784

785

786

787

788

789

790

791

792

793

794

795

796

797

798

799

800

801

802

803

804

805

806

807

808

809

810

811

812

813

814

815

816

817

818

819

820

821

822

823

824

825

826

827

828

compartmentalization and export. Journal of Pharmacology and Experimental Therapeutics 306:718-725. DOI: 10.1124/jpet.103.051284.

Hayashi T, Su TP. 2007. Sigma-1 Receptor Chaperones at the ER- Mitochondrion Interface Regulate Ca2+ Signaling and Cell Survival. Cell 131:596-610. DOI:

10.1016/J.CELL.2007.08.036.

Hirano K, Tagashira H, Fukunaga K. 2014. Cardioprotective Effect of the Selective Sigma-1

Receptor Agonist, SA4503. YAKUGAKU ZASSHI 134:707-713. DOI: 10.1248/yakushi.1300255-3.

Hoertel N, Sánchez-Rico M, Vernet R, Jannot A-S, Neuraz A, Blanco C, Lemogne C, Airagnes G, Paris N, Daniel C, Gramfort A, Lemaitre G, Bernaux M, Bellamine A, Beeker N, Limosin F. 2021. Observational study of haloperidol in hospitalized patients with COVID19. PLOS ONE 16:e0247122. DOI: 10.1371/journal.pone.0247122.

Huang C, Wang Y, Li X, Ren L, Zhao J, Hu Y, Zhang L, Fan G, Xu J, Gu X, Cheng Z, Yu T, Xia J, Wei Y, Wu W, Xie X, Yin W, Li H, Liu M, Xiao Y, Gao H, Guo L, Xie J, Wang G, Jiang R, Gao Z, Jin Q, Wang J, Cao B. 2020. Clinical features of patients infected with 2019 novel coronavirus in Wuhan, China. The Lancet 395:497-506. DOI: 10.1016/S01406736(20)30183-5.

Janssen SPM, Gayan-Ramirez G, Van Den Bergh A, Herijgers P, Maes K, Verbeken E, Decramer M. 2005. Interleukin-6 causes myocardial failure and skeletal muscle atrophy in rats. Circulation 111:996-1005. DOI: 10.1161/01.CIR.0000156469.96135.0D.

Karakikes I, Ameen M, Termglinchan V, Wu JC. 2015. Human Induced Pluripotent Stem CellDerived Cardiomyocytes: Insights into Molecular, Cellular, and Functional Phenotypes. Circulation Research 117:80-88. DOI: 10.1161/CIRCRESAHA.117.305365.

Krenz M, Robbins J. 2004. Impact of beta-myosin heavy chain expression on cardiac function during stress. Journal of the American College of Cardiology 44:2390-2397. DOI: 10.1016/J.JACC.2004.09.044.

Lenze EJ, Mattar C, Zorumski CF, Stevens A, Schweiger J, Nicol GE, Miller JP, Yang L, Yingling M, Avidan MS, Reiersen AM. 2020. Fluvoxamine vs Placebo and Clinical Deterioration in Outpatients With Symptomatic COVID-19. JAMA 324:2292. DOI: 10.1001/jama.2020.22760.

Lewis R, Li J, McCormick PJ, Huang CL-H, Jeevaratnam K. 2020. Is the sigma-1 receptor a potential pharmacological target for cardiac pathologies? A systematic review. International Journal of Cardiology. Heart \& Vasculature 26. DOI: 10.1016/J.IJCHA.2019.100449.

Lindner D, Fitzek A, Bräuninger H, Aleshcheva G, Edler C, Meissner K, Scherschel K, Kirchhof P, Escher F, Schultheiss HP, Blankenberg S, Püschel K, Westermann D. 2020. Association of Cardiac Infection with SARS-CoV-2 in Confirmed COVID-19 Autopsy Cases. JAMA Cardiology. DOI: 10.1001/jamacardio.2020.3551.

Lovato ECW, Barboza LN, Wietzikoski S, de Souza ANV, Auth PA, Junior AG, Dos Reis Lívero FA. 2020. Repurposing Drugs for the Management of Patients with Confirmed Coronavirus Disease 2019 (COVID-19). Current pharmaceutical design. DOI: $10.2174 / 1381612826666200707121636$.

Magadum A, Kishore R. 2020. Cardiovascular Manifestations of COVID-19 Infection. Cells 9:2508. DOI: 10.3390/cells9112508.

Marchiano S, Hsiang T-Y, Khanna A, Higashi T, Whitmore LS, Bargehr J, Davaapil H, Chang J, Smith E, Ong LP, Colzani M, Reinecke H, Yang X, Pabon L, Sinha S, Najafian B, Sniadecki NJ, Bertero A, Gale M, Murry CE. 2021. SARS-CoV-2 infects human pluripotent 
829

830

831

832

833

834

835

836

837

838

839

840

841

842

843

844

845

846

847

848

849

850

851

852

853

854

855

856

857

858

859

860

861

862

863

864

865

866

867

868

869

870

871

872

873

874

stem cell-derived cardiomyocytes, impairing electrical and mechanical function. Stem Cell Reports:2020.08.30.274464. DOI: 10.1016/j.stemcr.2021.02.008.

Morales-Lázaro SL, González-Ramírez R, Rosenbaum T. 2019. Molecular interplay between the sigma-1 receptor, steroids, and ion channels. Frontiers in Pharmacology 10. DOI: 10.3389/fphar.2019.00419.

Nguyen E, McCracken K, Liu Y, Pouw B, Matsumoto R. 2005. Involvement of sigma (sigma) receptors in the acute actions of methamphetamine: receptor binding and behavioral studies. Neuropharmacology 49:638-645. DOI: 10.1016/J.NEUROPHARM.2005.04.016.

Niehoff J, Matzkies M, Nguemo F, Hescheler J, Reppel M. 2019. The Effect of Antiarrhythmic Drugs on the Beat Rate Variability of Human Embryonic and Human Induced Pluripotent Stem Cell Derived Cardiomyocytes. Scientific Reports 9:1-10. DOI: 10.1038/s41598-01950557-7.

Novakova M, Ela C, Barg J, Vogel Z, Hasin Y, Eilam Y. 1995. Inotropic action of $\sigma$ receptor ligands in isolated cardiac myocytes from adult rats. European Journal of Pharmacology 286:19-30. DOI: 10.1016/0014-2999(95)00424-J.

Novakova M, Sedlakova B, Sirova M, Fialova K, Krizanova O. 2010. Haloperidol increases expression of the inositol 1,4,5-trisphosphate receptors in rat cardiac atria, but not in ventricles. General Physiology and Biophysics 29:381-389. DOI:

10.4149/gpb_2010_04_381.

Okuyama S, Imagawa Y, Ogawa S ichi, Araki H, Ajima A, Tanaka M, Muramatsu M, Nakazato A, Yamaguchi K, Yoshida M, Otomo S. 1993. NE-100, a novel sigma receptor ligand: In vivo tests. Life Sciences 53. DOI: 10.1016/0024-3205(93)90588-T.

Oslowski CM, Urano F. 2011. Measuring ER stress and the unfolded protein response using mammalian tissue culture system. Methods in enzymology 490:71. DOI: 10.1016/B978-012-385114-7.00004-0.

Page RL, O’bryant CL, Cheng D, Dow TJ, Ky B, Stein CM, Spencer AP, Trupp RJ, Lindenfeld JA. 2016. Drugs that may cause or exacerbate heart failure. Circulation 134:e32-e69. DOI: 10.1161/CIR.0000000000000426.

Pellicori P, Doolub G, Wong CM, Lee KS, Mangion K, Ahmad M, Berry C, Squire I, Lambiase PD, Lyon A, McConnachie A, Taylor RS, Cleland JGF. 2021. COVID-19 and its cardiovascular effects: a systematic review of prevalence studies. Cochrane Database of Systematic Reviews 2021. DOI: 10.1002/14651858.CD013879.

Perez-Bermejo JA, Kang S, Rockwood SJ, Simoneau CR, Joy DA, Silva AC, Ramadoss GN, Flanigan WR, Fozouni P, Li H, Chen P-Y, Nakamura K, Whitman JD, Hanson PJ, McManus BM, Ott M, Conklin BR, McDevitt TC. 2021. SARS-CoV-2 infection of human iPSC-derived cardiac cells reflects cytopathic features in hearts of patients with COVID-19. Science Translational Medicine:eabf7872. DOI: 10.1126/scitranslmed.abf7872.

Pointon A, Harmer AR, Dale IL, Abi-Gerges N, Bowes J, Pollard C, Garside H. 2015. Assessment of cardiomyocyte contraction in human-induced pluripotent stem cell-derived cardiomyocytes. Toxicological Sciences 144:227-237. DOI: 10.1093/toxsci/kfu312.

Qin J, Wang P, Li Y, Yao L, Liu Y, Yu T, Lin J, Fang X, Huang Z. 2019. Activation of Sigma-1 Receptor by Cutamesine Attenuates Neuronal Apoptosis by Inhibiting Endoplasmic Reticulum Stress and Mitochondrial Dysfunction in a Rat Model of Asphyxia Cardiac Arrest. Shock (Augusta, Ga.) 51:105-113. DOI: 10.1097/SHK.0000000000001119.

Ramakers C, Ruijter JM, Lekanne Deprez RH, Moorman AFM. 2003. Assumption-free analysis of quantitative real-time polymerase chain reaction (PCR) data. Neuroscience Letters 
875

876

877

878

879

880

881

882

883

884

885

886

887

888

889

890

891

892

893

894

895

896

897

898

899

900

901

902

903

904

905

906

907

908

909

910

911

912

913

914

915

916

917

918

919

920

339:62-66. DOI: 10.1016/S0304-3940(02)01423-4.

Reznikov LR, Norris MH, Vashisht R, Bluhm AP, Li D, Liao YSJ, Brown A, Butte AJ, Ostrov DA. 2020. Identification of antiviral antihistamines for COVID-19 repurposing.

Biochemical and Biophysical Research Communications. DOI: 10.1016/j.bbrc.2020.11.095. Ritzenthaler C, Elamawi R. 2006. The ER in replication of positive-strand RNA viruses. Plant Cell Monographs 4:309-330. DOI: 10.1007/7089_061.

Rosen DA, Seki SM, Fernández-Castañeda A, Beiter RM, Eccles JD, Woodfolk JA, Gaultier A. 2019. Modulation of the sigma-1 receptor-IRE1 pathway is beneficial in preclinical models of inflammation and sepsis. Science Translational Medicine 11. DOI:

10.1126/scitranslmed.aau5266.

Rothenbacher D, Müller-Scholze S, Herder C, Koenig W, Kolb H. 2006. Differential expression of chemokines, risk of stable coronary heart disease, and correlation with established cardiovascular risk markers. Arteriosclerosis, Thrombosis, and Vascular Biology 26:194199. DOI: 10.1161/01.ATV.0000191633.52585.14.

Rousseaux CG, Greene SF. 2016. Sigma receptors [ $\sigma$ Rs]: Biology in normal and diseased states. Journal of Receptors and Signal Transduction 36:327-388. DOI: 10.3109/10799893.2015.1015737.

Ruijter JM, Ramakers C, Hoogaars WMH, Karlen Y, Bakker O, van den hoff MJB, Moorman AFM. 2009. Amplification efficiency: Linking baseline and bias in the analysis of quantitative PCR data. Nucleic Acids Research 37. DOI: 10.1093/nar/gkp045.

Seftel D, Boulware DR. 2021. Prospective Cohort of Fluvoxamine for Early Treatment of Coronavirus Disease 19. Open Forum Infectious Diseases 8. DOI: 10.1093/ofid/ofab050.

Sequeira V, Nijenkamp LLAM, Regan JA, Van Der Velden J. 2014. The physiological role of cardiac cytoskeleton and its alterations in heart failure. Biochimica et Biophysica Acta Biomembranes 1838:700-722. DOI: 10.1016/j.bbamem.2013.07.011.

Sharma A, Garcia G, Wang Y, Plummer JT, Morizono K, Arumugaswami V, Svendsen CN. 2020. Human iPSC-Derived Cardiomyocytes Are Susceptible to SARS-CoV-2 Infection. Cell Reports Medicine 1:100052. DOI: 10.1016/j.xcrm.2020.100052.

Sharma A, McKeithan WL, Serrano R, Kitani T, Burridge PW, Álamo JC del, Mercola M, Wu JC. 2018. Use of human induced pluripotent stem cell-derived cardiomyocytes to assess drug cardiotoxicity. Nature Protocols 2018 13:12 13:3018-3041. DOI: 10.1038/s41596018-0076-8.

Shi S, Qin M, Shen B, Cai Y, Liu T, Yang F, Gong W, Liu X, Liang J, Zhao Q, Huang H, Yang B, Huang C. 2020. Association of Cardiac Injury with Mortality in Hospitalized Patients with COVID-19 in Wuhan, China. JAMA Cardiology 5. DOI:

10.1001/jamacardio.2020.0950.

Shinoda Y, Tagashira H, Bhuiyan MS, Hasegawa H, Kanai H, Fukunaga K. 2016a. Haloperidol aggravates transverse aortic constriction-induced heart failure via mitochondrial dysfunction. Journal of Pharmacological Sciences 131:172-183. DOI:

10.1016/j.jphs.2016.05.012.

Shinoda Y, Tagashira H, Bhuiyan MS, Hasegawa H, Kanai H, Zhang C, Han F, Fukunaga K. 2016b. Corticosteroids mediate heart failure-induced depression through reduced $\sigma 1-$ receptor expression. PLOS ONE 11. DOI: 10.1371/journal.pone.0163992.

Stracina T, Novakova M. 2018. Cardiac sigma receptors - An update. Physiological Research 67:S561-S576. DOI: 10.33549/physiolres.934052.

Stringer C, Wang T, Michaelos M, Pachitariu M. 2021. Cellpose: a generalist algorithm for

Peer] reviewing PDF | (2021:09:66092:1:0:NEW 10 Nov 2021) 
921

922

923

924

925

926

927

928

929

930

931

932

933

934

935

936

937

938

939

940

941

942

943

944

945

946

947

948

949

950

951

952

953

954

955

956

957

958

959

960

961

962

963

964

965

966

cellular segmentation. Nature Methods 18:100-106. DOI: 10.1038/s41592-020-01018-x.

Su TP, Hayashi T, Maurice T, Buch S, Ruoho AE. 2010. The sigma-1 receptor chaperone as an inter-organelle signaling modulator. Trends in Pharmacological Sciences 31:557-566. DOI: 10.1016/j.tips.2010.08.007.

Szabo A, Kovacs A, Frecska E, Rajnavolgyi E. 2014. Psychedelic N,N-dimethyltryptamine and 5-methoxy-N,N-dimethyltryptamine modulate innate and adaptive inflammatory responses through the sigma-1 receptor of human monocyte-derived dendritic cells. PloS one 9:e106533. DOI: 10.1371/journal.pone.0106533.

Tagashira H, Bhuiyan MS, Shioda N, Fukunaga K. 2014. Fluvoxamine rescues mitochondrial $\mathrm{Ca} 2+$ transport and ATP production through $\sigma 1$-receptor in hypertrophic cardiomyocytes. Life Sciences 95:89-100. DOI: 10.1016/j.1fs.2013.12.019.

Tagashira H, Fukunaga K. 2012. Cardioprotective Effect of Fluvoxamine, Sigma-1 Receptor High Affinity Agonist. YAKUGAKU ZASSHI 132:167-172. DOI: 10.1248/yakushi.132.167.

Tagashira H, Zhang C, Lu YM, Hasegawa H, Kanai H, Han F, Fukunaga K. 2013. Stimulation of $\sigma 1$-receptor restores abnormal mitochondrial $\mathrm{Ca} 2+$ mobilization and ATP production following cardiac hypertrophy. Biochimica et Biophysica Acta - General Subjects 1830:3082-3094. DOI: 10.1016/j.bbagen.2012.12.029.

Tarabová B, Nováková M, Lacinová L. 2009. Haloperidol moderately inhibits cardiovascular Ltype calcium current. General Physiology and Biophysics 28:249-259. DOI: $10.4149 / \mathrm{gpb} 200903249$.

Towbin H, Gordon J, Staehelin T. 1989. Immunoblotting in the Clinical Laboratory. Journal of Clinical Chemistry and Laboratory Medicine 27:495-502. DOI: 10.1515/cclm.1989.27.8.495.

Tummino TA, Rezelj V V., Fischer B, Fischer A, O’Meara MJ, Monel B, Vallet T, White KM, Zhang Z, Alon A, Schadt H, O’Donnell HR, Lyu J, Rosales R, McGovern BL, Rathnasinghe R, Jangra S, Schotsaert M, Galarneau J-R, Krogan NJ, Urban L, Shokat KM, Kruse AC, García-Sastre A, Schwartz O, Moretti F, Vignuzzi M, Pognan F, Shoichet BK. 2021. Drug-induced phospholipidosis confounds drug repurposing for SARS-CoV-2. Science 373:541-547. DOI: 10.1126/SCIENCE.ABI4708.

Vela JM. 2020. Repurposing Sigma-1 Receptor Ligands for COVID-19 Therapy? Frontiers in Pharmacology 11:1716. DOI: 10.3389/fphar.2020.582310.

Wang S, Binder P, Fang Q, Wang Z, Xiao W, Liu W, Wang X. 2018. Endoplasmic reticulum stress in the heart: insights into mechanisms and drug targets. British Journal of Pharmacology 175:1293. DOI: 10.1111/BPH.13888.

Watkins SJ, Borthwick GM, Oakenfull R, Robson A, Arthur HM. 2012. Angiotensin II-induced cardiomyocyte hypertrophy in vitro is TAK1-dependent and Smad2/3-independent. Hypertension Research 35:393-398. DOI: 10.1038/hr.2011.196.

Witchel HJ. 2011. Drug-induced hERG Block and Long QT Syndrome. Cardiovascular Therapeutics 29:251-259. DOI: 10.1111/j.1755-5922.2010.00154.x.

Wong CK, Luk HKH, Lai WH, Lau YM, Zhang RR, Wong ACP, Lo GCS, Chan KH, Hung IFN, Tse HF, Woo PCY, Lau SKP, Siu CW. 2020. Human-induced pluripotent stem cell-derived cardiomyocytes platform to study SARS-CoV-2 related myocardial injury. Circulation Journal 84:2027-2031. DOI: 10.1253/circj.CJ-20-0881.

Wu L, O’Kane AM, Peng H, Bi Y, Motriuk-Smith D, Ren J. 2020. SARS-CoV-2 and cardiovascular complications: From molecular mechanisms to pharmaceutical management. Biochemical Pharmacology 178. DOI: 10.1016/j.bcp.2020.114114. 
967

968

969

970

971

972

973

974

975

976

977

978

979

980

981

982

983
Yang J, Zheng Y, Gou X, Pu K, Chen Z, Guo Q, Ji R, Wang H, Wang Y, Zhou Y. 2020. Prevalence of comorbidities and its effects in coronavirus disease 2019 patients: A systematic review and meta-analysis. International Journal of Infectious Diseases 94:9195. DOI: 10.1016/j.ijid.2020.03.017.

Yao XH, Li TY, He ZC, Ping YF, Liu HW, Yu SC, Mou HM, Wang LH, Zhang HR, Fu WJ, Luo T, Liu F, Chen C, Xiao HL, Guo HT, Lin S, Xiang DF, Shi Y, Li QR, Huang X, Cui Y, Li XZ, Tang W, Pan PF, Huang XQ, Ding YQ, Bian XW. 2020. [A pathological report of three COVID-19 cases by minimally invasive autopsies]. Zhonghua bing li xue za zhi= Chinese journal of pathology 49:E009. DOI: 10.3760/cma.j.cn112151-20200312-00193.

Youker K, Smith CW, Anderson DC, Miller D, Michael LH, Rossen RD, Entman ML. 1992. Neutrophil adherence to isolated adult cardiac myocytes: Induction by cardiac lymph collected during ischemia and reperfusion. Journal of Clinical Investigation 89:602-609. DOI: 10.1172/JCI115626.

Zhou R, Chen SH, Li G, Chen HL, Liu YX, Wu HM, Wang Y, Feng J, Hong JS. 2019. Ultralow doses of dextromethorphan protect mice from endotoxin-induced sepsis-like hepatotoxicity. Chemico-Biological Interactions 303:50-56. DOI: 10.1016/j.cbi.2019.02.025. 


\section{Figure 1}

Human induced pluripotent stem cell-derived cardiomyocytes (hiPSC-CMs) express 850 the Sigma-1 receptor (S1R).

(A) End point PCR analysis of S1R on mRNA isolated from three hiPSC-CMs replicate samples from three independent batches of differentiation $(\mathrm{N}=3)$. GAPDH was used as housekeeping control of mRNA samples. Uncropped agarose gel is appended in Supplemental Figure S5 with appropriate controls. (B) Representative western blot of S1R expression in protein extracts of control hiPSC-CMs. Actin was used as a loading control. The detection of the protein was performed in samples from 3 different batches with similar results $(N=3)$. Fulllength gels of the representative blots shown here are presented in Supplemental Figure S5. (C) Representative image of staining performed in fixed cardiomyocytes from 3 different batches shows S1R presence and similar distribution in hiPSC-CMs $(N=3)$. S1R (green); phalloidin (red) and nuclei (blue); scale bar $=50 \mu \mathrm{m}$. (D) Immunofluorescence shows mitochondrial marker VDAC1/Porin (red) and S1R (green) in hiPSC-CMs. Representative image of 3 independent experiments $(\mathrm{N}=3)$. Nuclei were stained with DAPI (blue); scale bar $=$ $50 \mu \mathrm{m}$. (E) Immunofluorescence shows ER chaperone lectin Calnexin (CNX) (red) and S1R (green) in hiPSC-CMs. Representative image of 3 independent experiments $(\mathrm{N}=3)$. Nuclei were stained with DAPI (blue); scale bar $=50 \mu \mathrm{m}$. Zoom-in highlights the cells indicated by the arrowheads (D and $E)$. 
A

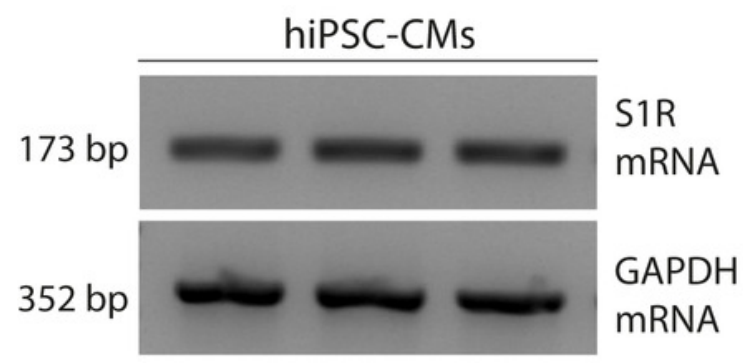

B

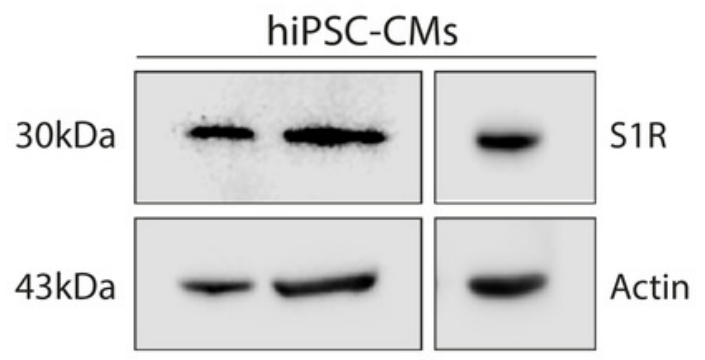

C
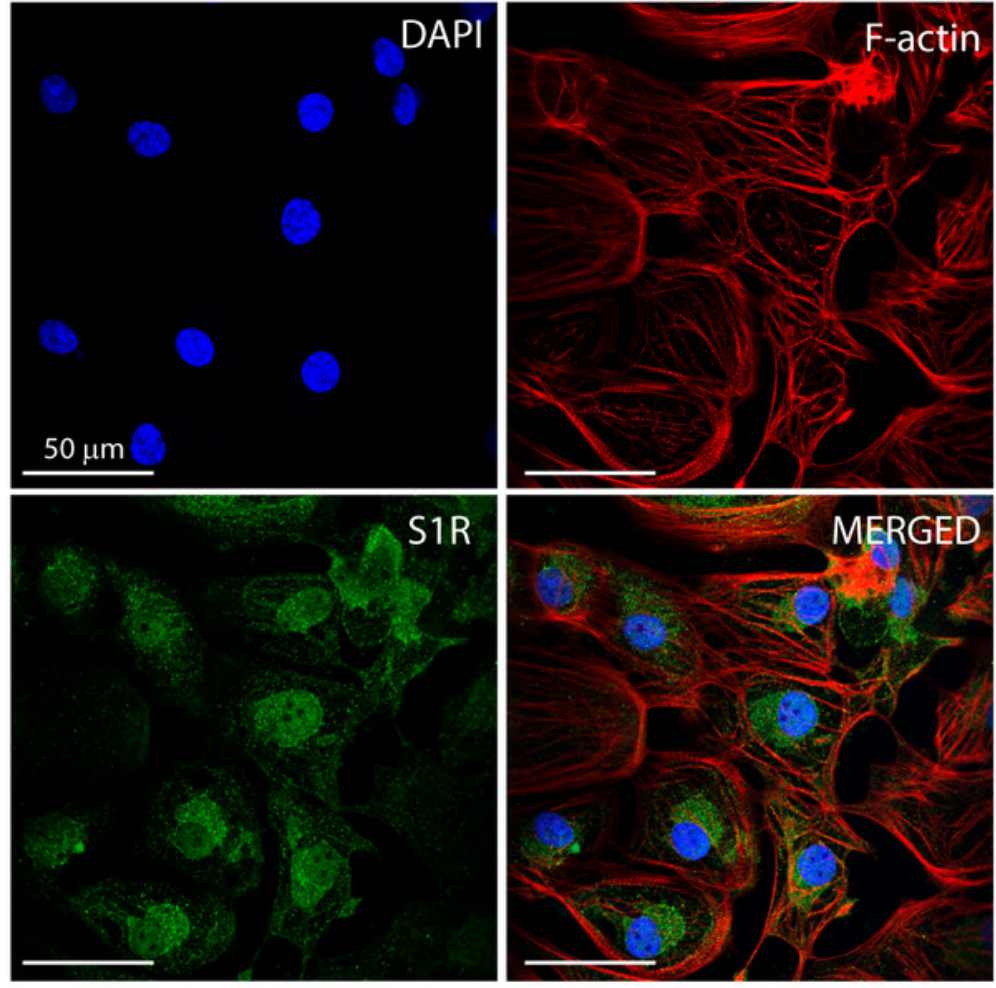

D
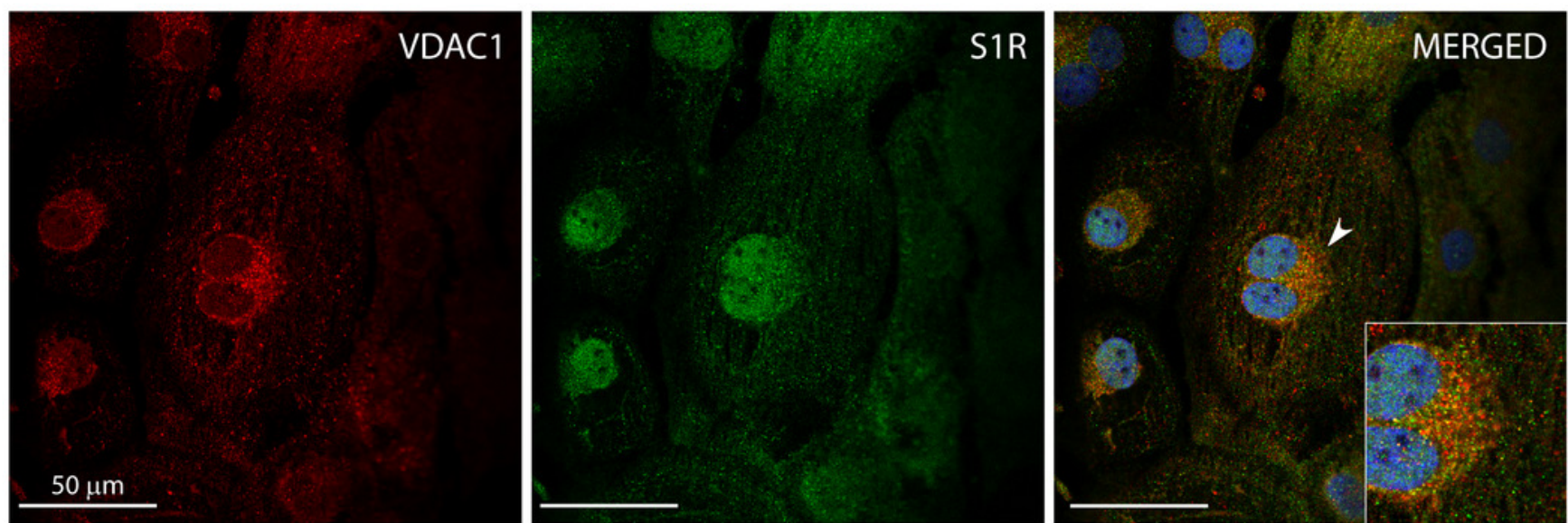

$\mathrm{E}$
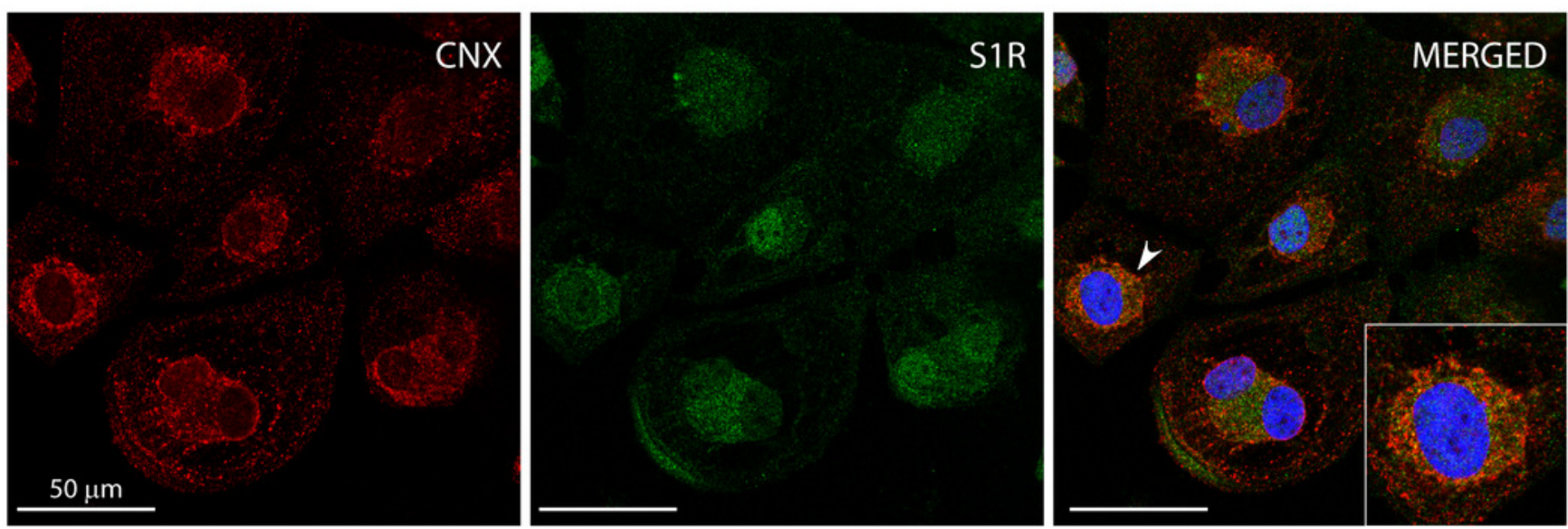


\section{Figure 2}

S1R inhibition reduces SARS-CoV-2 infection, replication, and cytotoxicity in hiPSC-CMs

(A) hiPSC-CMs were pre-treated for $24 \mathrm{~h}$ with $1 \mu \mathrm{M}$ NE-100 and infected with SARS-CoV-2 at multiplicity of infection (MOI) of 0.1 . Cells were evaluated at 48 hours post-infection (h.p.i). Representative immunostaining images show infected hiPSC-CMs positively stained for convalescent serum (CS) in red and no signal detection in mock conditions ( $N=3$ ); scale bar $=100 \mu \mathrm{m}$. (B) The percentage of infected hiPSC-CMs was assessed by quantification of CS positive cells in SARS-CoV-2-infected and mock-infected conditions exposed or not to S1R high-affinity antagonist NE-100 ( $N=3$ ). (C) Plaque forming units assay for the supernatants of the SARS-CoV-2 infected hiPSC-CMs ( $N=4)$. (D) Cell death was measured in the supernatant by LDH activity at $24,48(\mathrm{~N}=3)$ and 72 h.p.i $(\mathrm{N}=2)$. Data are represented as the mean \pm S.E.M, analyzed by Nested t-test $(p=0.0003)(B)$, unpaired two-tailed Welch's t-test $(p=0.0336)(C)$ and ordinary one-way ANOVA followed by Holm-Sidak's post-hoc ( $24 \mathrm{~h}$ $p=0.0089 ; 48 h p<0.0001$ and $p=0.0001)(D)$. Data points represent independent experiments. $* p<0.05, * * p<0.01,{ }^{* * *} p<0.001, * * * * p<0.0001$. 

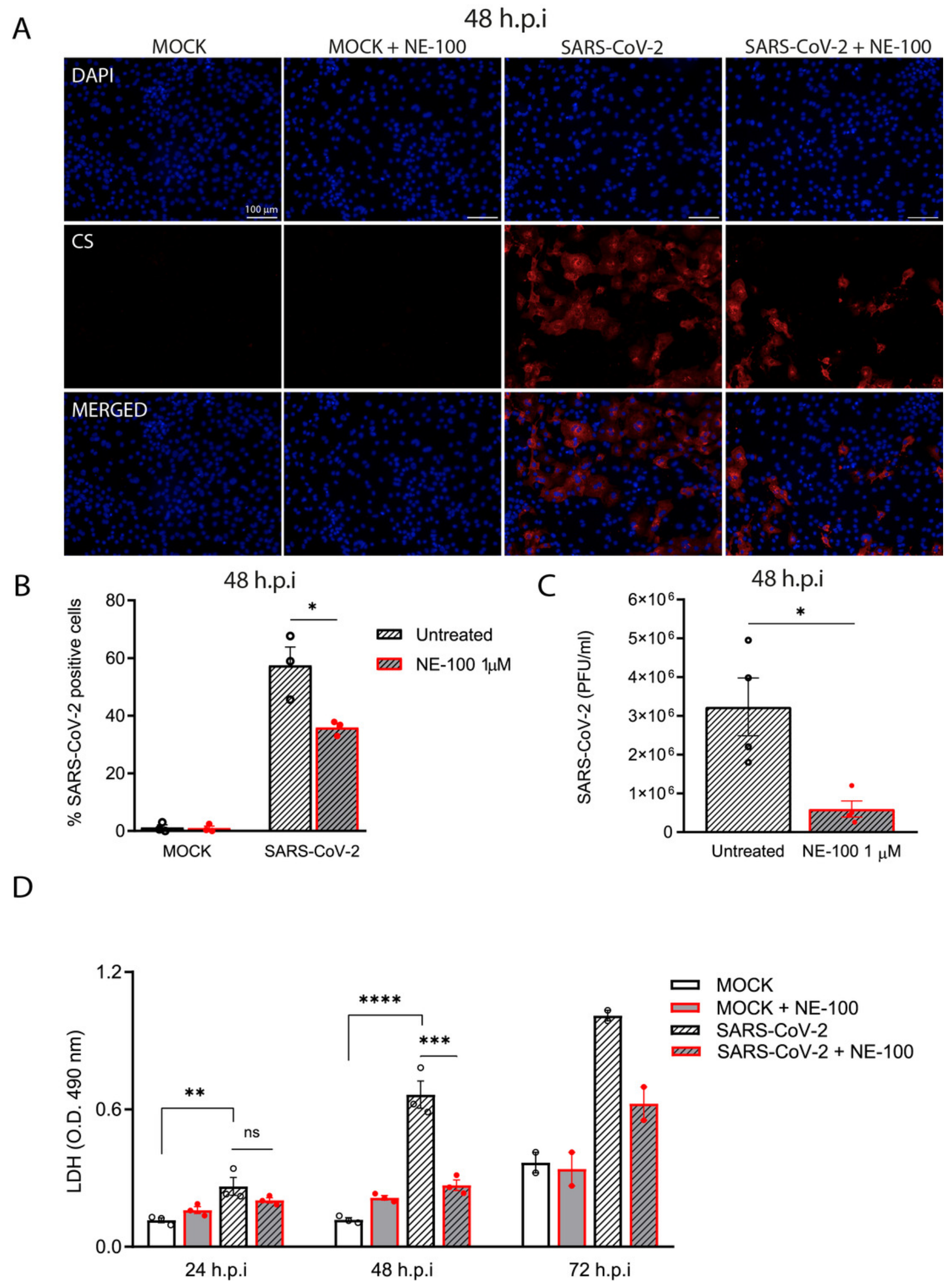

Peer) reviewing PDF | (2021:09:66092:1:0:NEW 10 Nov 2021) 


\section{Figure 3}

NE-100 decreases cytokine release that follows SARS-CoV-2 infection in hiPSC-CMs

(A and B) hiPSC- hiPSC-CMs were pre-treated or not with NE-100 $1 \mu \mathrm{M}$ and infected with SARS-CoV-2. Supernatants were analyzed by ELISA for IL-6, IL-8 and TNF- $\alpha$ at 24 h.p.i (IL-6 $p=0.0006$ and $p=0.0395 ; \mathrm{IL}-8 p=0.0661$ and $p=0.1426$; TNF- $\alpha p=0.0033$ and $p=0.0077$ ) (A) and 48 h.p.i (IL-6 $p<0.0001$ and $p=0.0009$; IL- $8 p=0.0001$ and $p=0.0017$; TNF- $\alpha p=0.1663$ and $p=0.5359)(B)(N=3)$. Data were normalized to the mean control value of each experiment and represents the mean \pm SEM of fold increase, analyzed by ordinary one-way ANOVA with Holm-Sidak's post-hoc. Data points represent independent experiments. $* \mathrm{p}<0.05,{ }^{* *} \mathrm{p}<0.01,{ }^{* * *} \mathrm{p}<0.001,{ }^{* * * *} \mathrm{p}<0.0001$. 
A

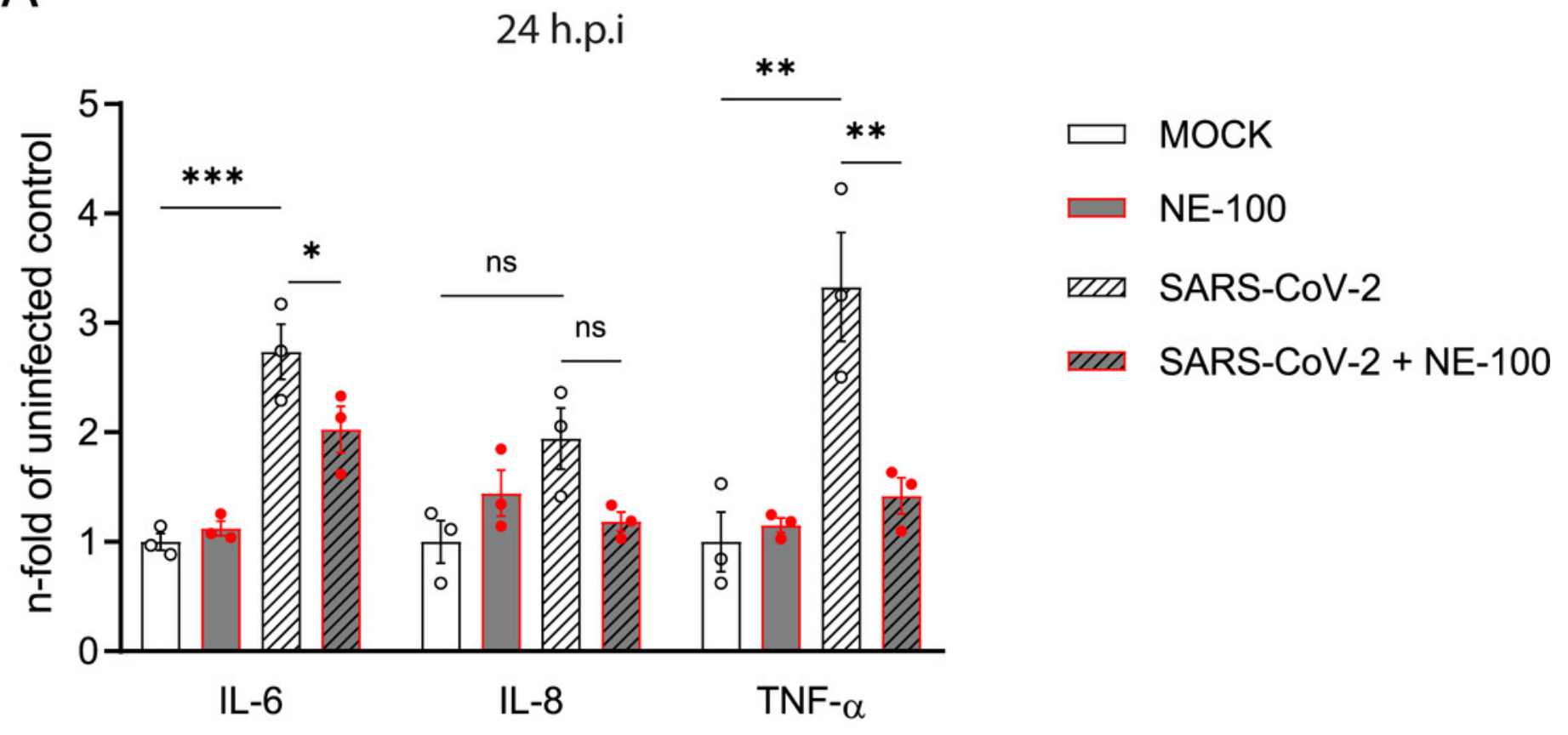

B

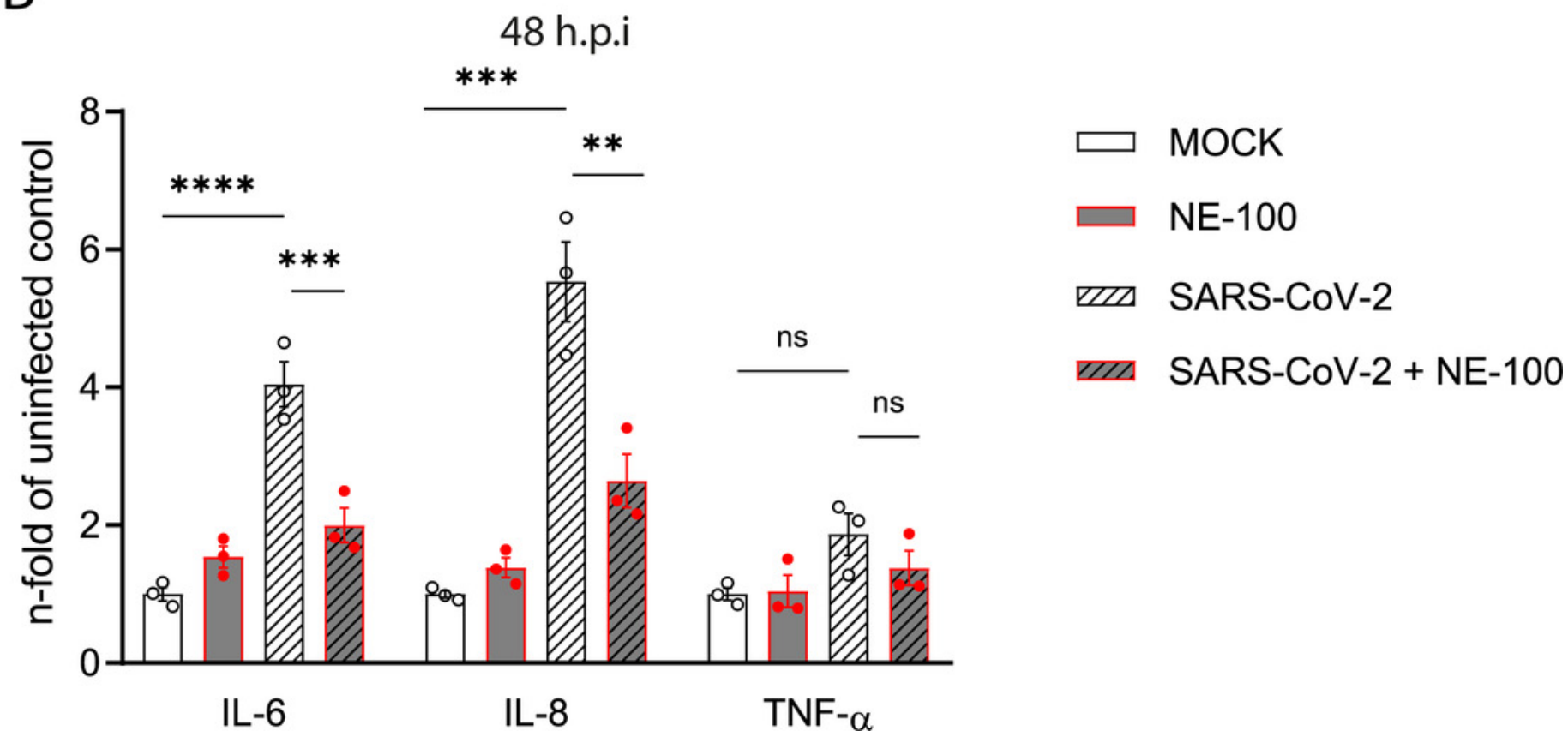




\section{Figure 4}

NE-100 does not induce death and ER stress but decreases beating frequency in hiPSCCMS

(A) Neutral red cell viability assay for escalating NE-100 concentrations shows non-significant changes after 72 hours post-treatment. Data are represented as the baseline-corrected mean \pm S.E.M relative to the vehicle condition analyzed by one-way ANOVA $(N=3)$. (B) Nuclear size analysis by DAPI staining shows the percentage of pyknotic nuclei after $48 \mathrm{~h}(\mathrm{~N}=3)$; Dots represent the percentage of each well evaluated in three independent experiments analyzed by unpaired Welch's $t$ test; non-significant $(p=0.1738)$. (C) Normalized mRNA expression of spliced and unspliced XBP1 transcripts in samples from different batches exposed to NE-100 $1 \mu \mathrm{M}$ in four independent experiments $(\mathrm{N}=4)$. Data are expressed relative to total XBP1 normalized expression \pm S.E.M and were analyzed by multiple t-tests (Holm-Sidak method) (spliced/total $p=0.7338$ and unspliced/total $p=0.6943$ ). (D) CHOP mRNA in samples from different batches exposed to NE-100 $1 \mu \mathrm{M}$ in three independent experiments $(\mathrm{N}=3)$. Values are expressed as fold-change relative to the untreated condition \pm S.E.M and were analyzed by unpaired Welch's $t$ test; non-significant $(p=0.5512)$. (E) Average of beats per minute analyzed 24 and $48 \mathrm{~h}$ after exposure to $\mathrm{NE}-100$ or vehicle $(\mathrm{N}=3)$. Data are presented as the average \pm S.E.M, statistical differences were analyzed by multiple t-tests (Holm-Sidak method) (24h $p=0.03663 ; 48 h p=0.00349$ ). 
A

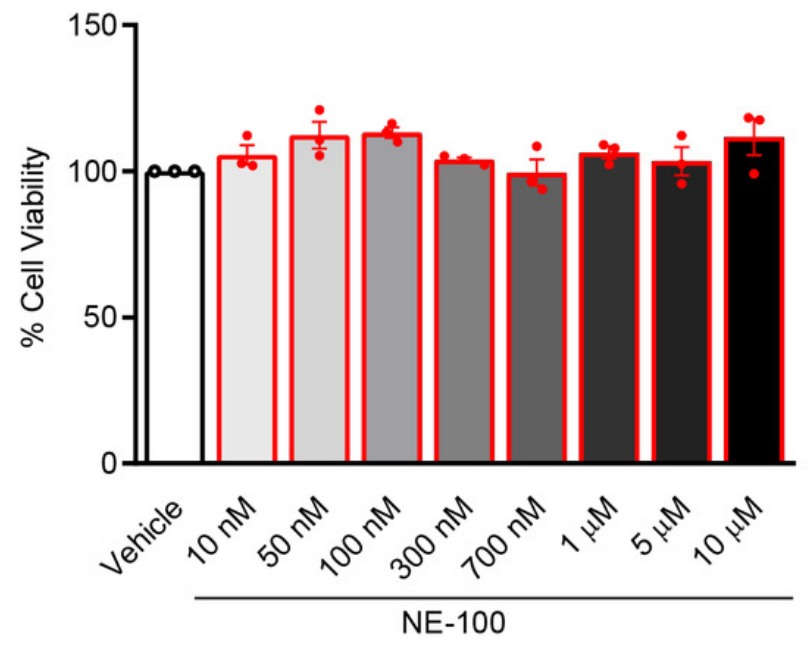

B

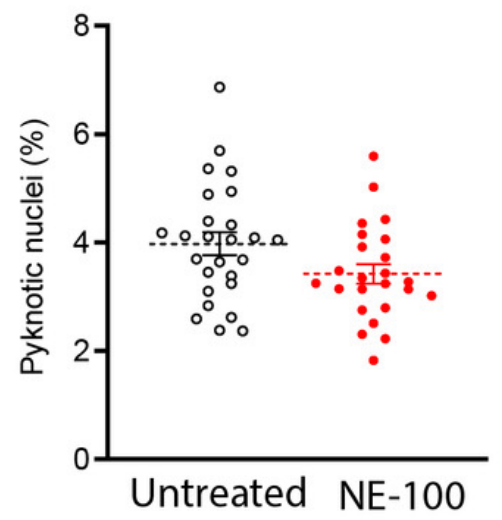

C

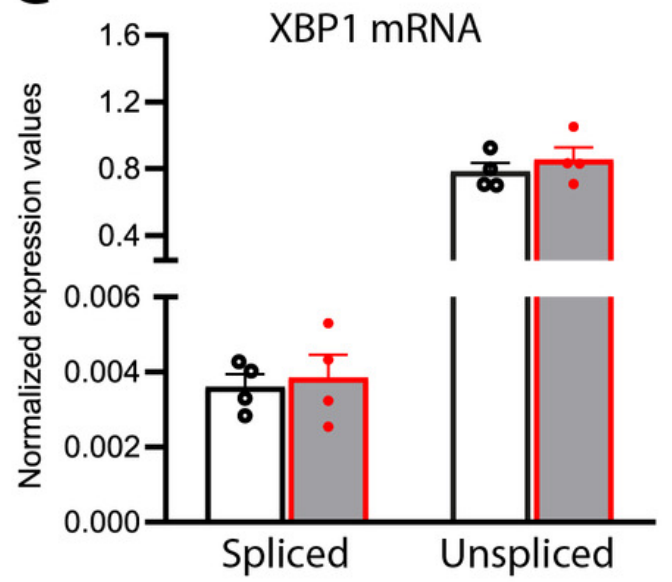

E

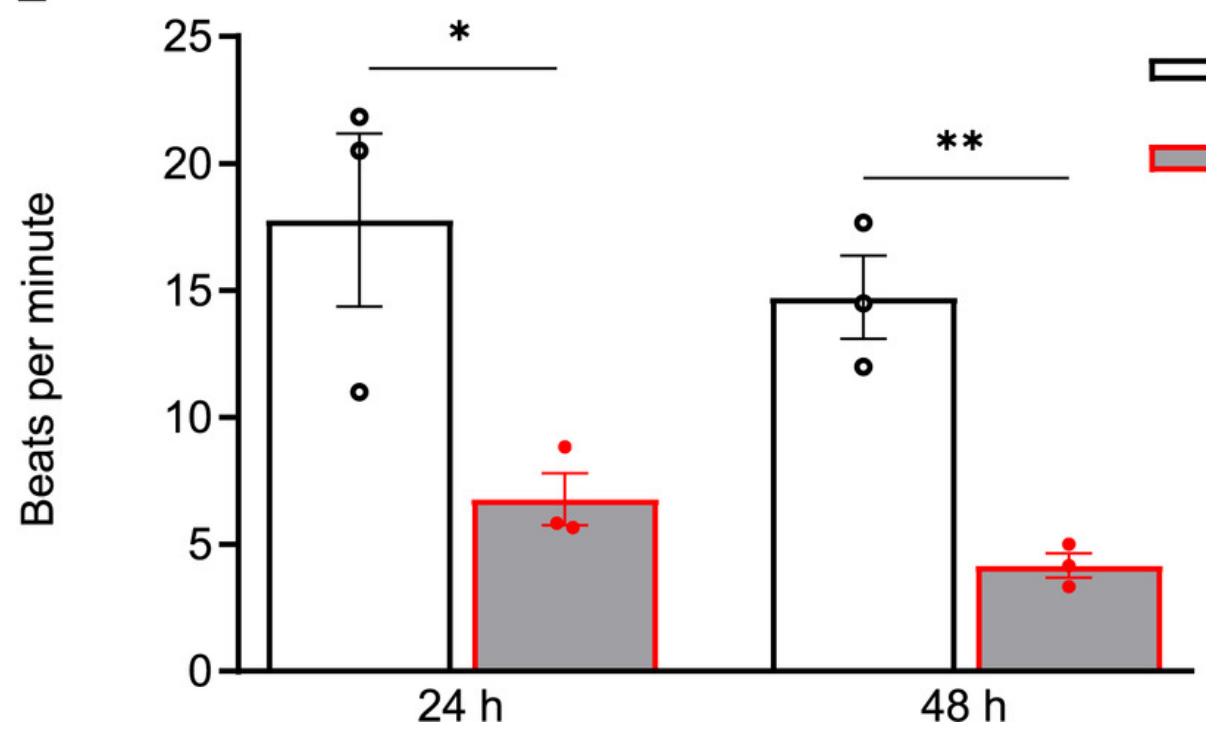

D

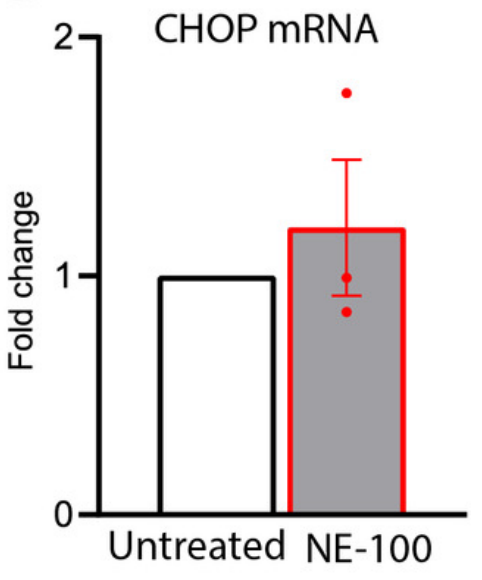




\section{Figure 5}

S1R inhibition downregulates the expression of structural-related genes and compromise cytoskeletal integrity

(A) Real-time qPCR shows decreased levels of transcript content for ANP after S1R inhibition $(\mathrm{N}=4)$. (B) Cell area was quantified by F-actin staining and shows a significant decrease in cell body sizes after exposure to NE-100 for $48 \mathrm{~h}$. Data represents distribution of surface area measured from approximately 24000 cells in four independent experiments $(N=4)$. (C) Changes in myofibril and cytoskeletal-related gene expression after 24h of NE-100 $1 \mu \mathrm{M}$ exposure from at least three replicates obtained from independent experiments $(\mathrm{N}=3$ or $\mathrm{N}=4$ ). ( $\mathrm{D}$ and E) Quantification of CTnT immunoreactive area and intensity, normalized by the total number of cells per field; values are expressed relative to untreated controls (D) or arbitrary units, and data points represent mean cTnT intensity per well (E) $(N=4)$. (F) Representative confocal images show in more detail the disruption of F-actin and CTnT organization, observed in at least four independent repeats $(N=4)$. Scale bar $=50 \mu \mathrm{m}$. Data are presented as the average \pm S.E.M, statistical differences were analyzed by unpaired Welch's t-test ( $p=0.0081$ and $p=0.0262)(A$ and $D)$, nested t-test $(p=0.0108)(B)$, multiple ttests (Holm-Sidak method) (ACTN1 $\mathrm{p}=0.8478$, ACTN2 $\mathrm{p}=0.000004$, ACTA1 $\mathrm{p}<0.000001$, TNN13 $\mathrm{p}=0.0011$, TNNT1 $\mathrm{p}=0.0001$, MYH6 $\mathrm{p}=0.0502$, MYH7 $\mathrm{p}=0.1582$ ) (C), and MannWhitney test $(p=0.0235)(E)$. Data points represent independent experiments unless otherwise stated. $* p<0.05 ;{ }^{* *} p<0.01 ; * * *<<0.001 ; * * * * p<0.0001$. 
A

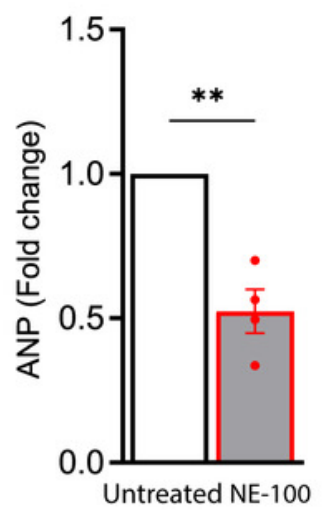

D

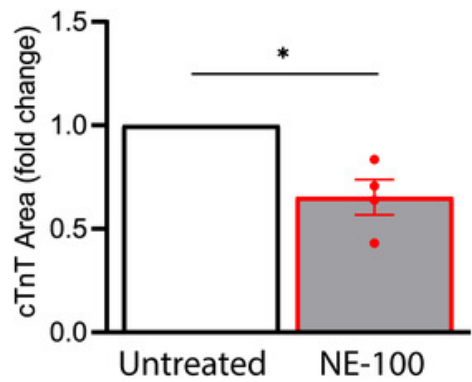

E

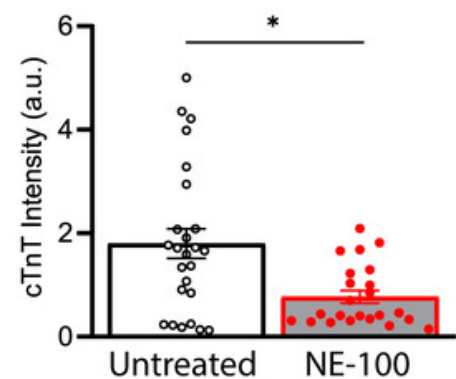

B

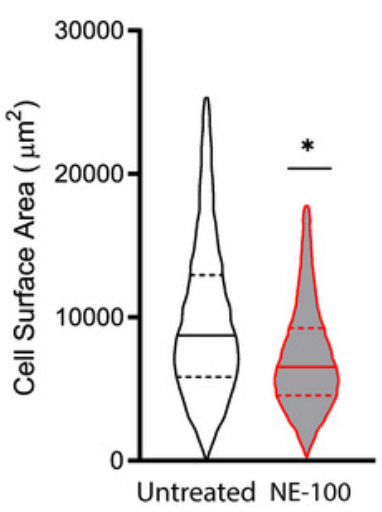

F
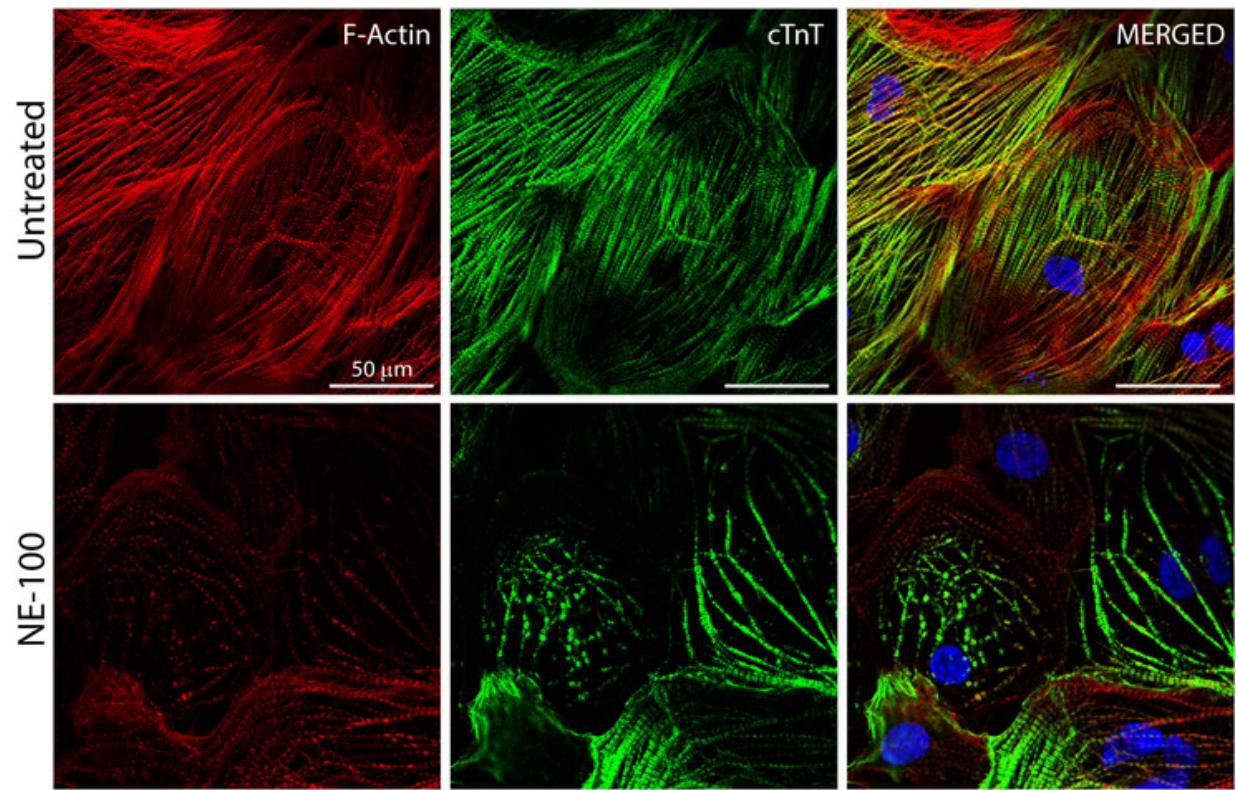